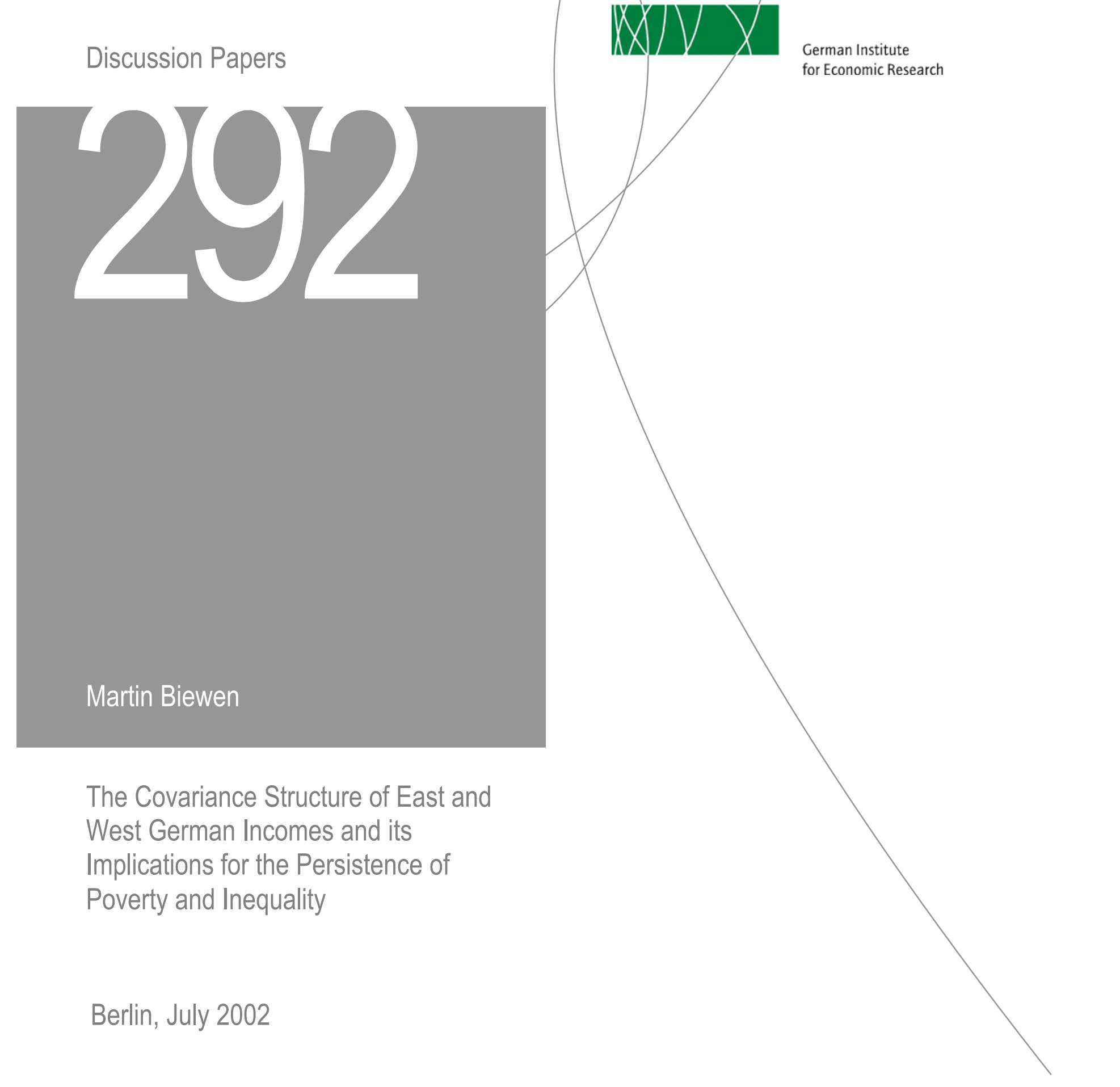


Opinions expressed in this paper are those of the author and do not necessarily reflect views of the Institute.

\section{DIW Berlin}

\section{German Institute}

for Economic Research

Königin-Luise-Str. 5

14195 Berlin,

Germany

Phone +49-30-897 89-0

Fax +49-30-897 89-200

www.diw.de

ISSN 1619-4535 


\title{
The Covariance Structure of East and West German In- comes and its Implications for the Persistence of Poverty and Inequality ${ }^{1}$
}

\author{
Martin Biewen \\ University of Heidelberg \\ IZA, Bonn \\ DIW Berlin
}

\begin{abstract}
Using data from the German Socio-Economic Panel (GSOEP), this paper analyzes the dynamics of equivalent income in Germany in the eighties and nineties. Special emphasis is given to the separation of permanent and transitory components, the persistence of transitory shocks and their implications for the persistence of poverty and income inequality. The results suggest that 52 to 69 percent of income inequality in West Germany were due to permanent differences between individuals and that poor individuals stayed in poverty for two years on average. In East Germany, the contribution of the permanent component to overall income inequality increased from 20 percent in 1990 to over 70 percent in 1998 and the persistence of poverty rose accordingly. The paper also looks at the special situation of population subgroups such as lone mothers, 'double income no kids' households, couples with children and pensioners.
\end{abstract}

JEL-Classification: C23, D31, I32

Keywords: Covariance structure, Poverty, Inequality, Mobility,

Correspondence:

Martin Biewen, Alfred-Weber Institut, University of Heidelberg, Grabengasse 14, 69117 Heidelberg, Germany, Fax: +49-6221-543640, martin.biewen@mail.awi.uni-heidelberg.de

\footnotetext{
${ }^{1}$ I would like to thank Stephen P. Jenkins, Lorenzo Cappellari and Christoph M. Schmidt for helpful discussions and comments. This paper is part of the research programme of the TMR Network 'Living Standards, Inequality and Taxation'. Financial support of the European Union (Contract \#ERBFMRXCT980248) as well as the UK Economic and Social Research Council and the Deutsche Forschungsgesellschaft (DFG) is gratefully acknowledged. The data were made available by the German Socio Economic Panel Study (GSOEP) at the German Institute for Economic Research (DIW), Berlin.
} 


\section{Introduction}

Cross-sectional analyses of inequality and poverty provide snapshots of the income distribution at particular points of time. They can be criticized however, because they ignore the longitudinal dimension of these phenomena. For example, poverty may be seen as less of a problem if it is unlikely to persist for more than one period and inequality may be less severe if income differences average out over time. For this reason, it is necessary to complement cross-sectional analyses of inequality and poverty with an analysis of their persistence.

A natural way to think about the persistence of income processes is to decompose incomes into a permanent and a transitory component and to determine to what extent phenomena such as poverty and inequality are due to permanent differences between individuals rather than to transitory income fluctuations. The separation of permanent and transitory components has also implications for the structure of income mobility, as a large permanent component or a high persistence of the transitory component imply a low level of income mobility.

More importantly, it has implications for policy. If poverty and inequality are purely transitory, anti-poverty or inequality reducing policies are less urgent, because the problem is not as severe as it might seem from a cross-sectional analysis. On the other hand, a large permanent income component means that policies aiming at reducing inequality will have a limited effect unless they tackle the underlying permanent differences between individuals, i.e. persistent differences in education, employment and living arrangements. Similar things can be said about poverty. If a large part of poverty is of a highly persistent nature, only policies targeting the permanent characteristics responsible for poverty will be effective. This, of course, raises the general question of what the characteristics associated with poverty and inequality are, and to what extent they are of a permanent and to what extent of a transitory nature.

This paper employs covariance structure models to study these questions for Germany in the nineteen eighties and nineties. Until now, such models have mainly been used to describe the evolution of labour earnings over time. ${ }^{2}$ However, as labour earnings tell only part of the story in a country like Germany which is characterized to a large extent by state interventions in the income distribution, many of them at the household level, the focus will be on equivalized personal income rather than on individual earnings. Equivalized income is defined as household income adjusted for household size.

\footnotetext{
${ }^{2}$ Examples for such studies are Lillard/Willis (1978), Lillard/Weiss (1979), MaCurdy (1982), Abowd/Card (1989), Moffitt/Gottschalk (1995) and Baker (1997) for the United States, Burkhauser et al. (1997) for the United States and Germany, Dickens (2000) and Ramos (2001) for Great Britain and Cappellari (2000) for Italy. Atkinson et al. (1992) give an overview over the literature to that date.
} 
Moreover, since the situation in the formerly socialist East of Germany has been very different from that in West Germany in many respects during the period under consideration, the analysis is carried out for East and West separately. The east German income distribution underwent some drastic changes in the years following reunification and the question is to what extent the conditions in East Germany have already converged to those in West Germany.

Large parts of the methodology used in this paper build on the work of Lillard/Willis (1978). However, their analysis of low income states is extended to other parts of the distribution so that persistence of income states other than poverty can be addressed as well. In contrast to many other studies, covariates of income are used extensively, making much of the analysis multivariate. This allows one to analyze the contribution of observed characteristics to poverty and inequality and to look at the special situation of population subgroups which are of particular interest from a policy view, such as lone mothers, pensioners or households affected by unemployment.

The use of an income measure derived from household information also raises a statistical issue that has not been addressed in the literature. The fact that equivalent incomes of individuals are dependent across household members invalidates conventional statistical inference procedures based on independent observations. This has not been taken into account in studies that use such income measures (see Duncan (1983), Stevens (1999), Fourarge/Muffels (2000) and Devicienti (2001)). This paper offers a solution to this difficulty, provides appropriate standard errors and test statistics and shows that inference based on independent observations can yield misleading results.

The rest of the paper is organized as follows. Section 2 gives a description of the data which was taken from the German Socio-Economic Panel (GSOEP). Section 3 discusses the methodological strategy. The empirical results for different subpanels of the GSOEP are presented in section 4. Section 5 summarizes these results and offers some concluding remarks.

\section{Data}

The empirical analysis in this paper uses data from the German Socio-Economic Panel (GSOEP) (see Wagner et al. (1993) and SOEP Group (2001)). The GSOEP is a representative panel study for Germany which was started in 1984 for West Germany and extended to East Germany after reunification in 1990. In this paper, three different longitudinal subsamples of the GSOEP are used. In order to be able to compare East and West Germany, the years 1990 to 1998 were chosen to form one sample for West Germany and one for East Germany. This leaves a third sample consisting of 
data for the years 1984 to 1990 for West Germany, which is used for a long-term comparison. ${ }^{3}$

The unit of analysis is the individual, although all of the individual's characteristics are derived from household information. The econometric methods used in the next section require that individuals are included in a sample only if they were present in all the years that define the sample, i.e. all three samples are balanced. Samples sizes are 6219, 3050 and 8026, respectively. In order to account for differing sampling probabilities and attrition, longitudinal sample weights are used throughout the paper. $^{4}$

The analysis focuses on equivalized individual income $x=h / e(\theta)$, where $h$ denotes household income and $e(\theta)$ is an equivalence scale dependent on household type $\theta$. The equivalence scale used here is the the conventional OECD-scale which deflates household income by the square root of household size, i.e. $e(\theta)=\sqrt{s}$ for household size $s$. The GSOEP monthly net household income variable serves as the basis for all income calculations. It is the answer to a survey question directed to each household reference person which asked him or her to provide an estimate of total income of all household members, inclusive of transfers and after deduction of taxes and social security contributions.

The variables that are considered as potential covariates of equivalent income are shown in the first two columns of Table 1. In general, they characterize the age, employment and education structure of the individual's household, its nationality, the gender of its head as well as whether the household was resident in East Germany. Note that these variables are household characteristics rather than individual characteristics. This is due to the fact that equivalent income is a function of household income which depends not only on the characteristics of the individual in question but also on the characteristics of all other household members.

\section{— Table 1 about here -}

In detail, the variables shown in Table 1 are defined as follows. 'Living in East', 'female household head' and 'non-German' are dummies that indicate whether a household was resident in East Germany, ${ }^{5}$ whether it was headed by a woman and whether it was of non-German nationality. The rest of the variables represent the number of household members in different age, employment and education categories. The hierarchical structure ensures a consistent representation of household characteristics. ${ }^{6}$

\footnotetext{
${ }^{3}$ Results for this subsample will not be reported in detail.

${ }^{4}$ See Haisken-DeNew/Frick (2000), pp. 120 -133 for details how these weights were generated.

${ }^{5}$ Note that, for example, members of the east German sample may have moved to West Germany during the sample period.

${ }^{6}$ For example, it would not be possible to combine variables such as 'the number of university educated per-
} 
The employment status categories 'employed', 'unemployed' and 'retired' are mutually exclusive. (Individuals who would fall into more than one category are counted as belonging only to the first of the three categories.) Both full-time and part-time work are considered in deciding whether to define an individual as employed. An individual counts as unemployed if he or she is registered as such with the Arbeitsamt. The retirement status variable is the answer to the question whether the individual was retired in the calendar year before the interview. All other individuals belong to the 'other' category and can in general be characterized as economically inactive. Skill level is defined using information about educational qualifications. 'High-skilled' refers to individuals holding a university degree, whereas 'medium-skilled' means high-school degree ('Abitur') and/or occupational training. All other persons are counted as 'low-skilled'.

\section{Methodological setup}

In this paper, the dynamics of log equivalent income $y_{i t}$ are modelled as

$$
y_{i t}=x_{i t}^{\prime} \beta_{t}+u_{i t}
$$

for individuals $i=1 \ldots N$ and periods $t=1 \ldots T$, where $x_{i t}$ is a $K \times 1$-vector of household characteristics including a constant and $\beta_{t}$ is a time-dependent parameter-vector. The model is estimated in two variants, with and without covariates. In the case without covariates, just a time-varying constant is fitted, i.e. $x_{i t} \equiv 1$. The residual $u_{i t}$ is assumed to be decomposable into a permanent and a transitory component

$$
u_{i t}=\alpha_{t} \mu_{i}+\lambda_{t} v_{i t}
$$

where the permanent component $\alpha_{t} \mu_{i}$ consists of time-invariant characteristics $\mu_{i}$ which are weighted by a time-varying weight $\alpha_{t}$, and the transitory component $\lambda_{t} v_{i t}$ is given by an $\operatorname{ARMA}(1,1)$ process

$$
v_{i t}=\rho v_{i t-1}+\theta \varepsilon_{i t-1}+\varepsilon_{i t}
$$

which is multiplied by another time-varying weight $\lambda_{t}$ (similar models have been estimated by Dickens (2000), Cappellari (2000), Devicienti (2001) and Ramos (2001)).

In this model, the permanent component can be interpreted as the level to which incomes revert after a transitory shock has decayed or the level that would prevail if there were no transitory shocks at all (and everything stayed the same, i.e. $\alpha_{t}$ holding constant). The individual effect $\mu_{i}$ stands for sons in the household' and 'the number of adults aged 18 - 41 years' as these characteristics are not independent of each other. 
unobserved characteristics that do not change over the sample period. The weight $\alpha_{t}$ can then be seen as the 'price' for these characteristics, i.e. their average valuation in terms of income.

By contrast, the transitory component stands for shocks that occur in one period and that potentially persist over several periods. While the autoregressive part models the rate of decay or the persistence of these shocks, a moving-average part with a negative parameter can be interpreted as a compensatory reaction to a past transitory shock. For example, an accident or bad luck in a past period might be tried to made up for by working longer hours in the next period. Other examples of transitory shocks could include transitory unemployment, transitory job changes or measurement error that is correlated over periods.

One might wonder how shocks of a more permanent nature such as the birth of an additional child (if the number of children is unobserved) or other permanent changes in household structure fit into this framework. In the present model such shocks would only increase the persistence of the transitory component, which is always the average persistence of all kinds of shocks with potentially very different degrees of persistence. A way to model permanent shocks explicitly would be to let $\mu_{i}$ develop according to a random walk. (This has been done for earnings dynamics by cohort by Dickens (2000) and by Cappellari (2000).) However, this has the implausible implication of an ever increasing variance of log income, i.e. of ever increasing income inequality, which is clearly not supported by the data used here (see next section). ${ }^{7}$

Under the assumption $E\left(\mu_{i}\right)=E\left(v_{i t}\right)=E\left(\varepsilon_{i t}\right)=0$ and $E\left(\mu_{i} \varepsilon_{i t}\right)=E\left(\varepsilon_{i t} \varepsilon_{j s}\right)=0$ for all $i$ and $j$ and for all $t \neq s$, the covariance structure of the model is given by

$$
\operatorname{cov}\left(u_{i t} u_{i s}\right)=\alpha_{t} \alpha_{t-s} \sigma_{\mu}^{2}+\lambda_{t} \lambda_{t-s} E\left(v_{i t} v_{i t-s}\right)
$$

with

$$
E\left(v_{i t} v_{i t-s}\right)= \begin{cases}\sigma_{v_{0}}^{2} & , \quad t=0, s=0 \\ \rho^{2} E\left(v_{i t-1} v_{i t-1}\right)+\sigma_{\varepsilon}^{2}\left(1+\theta^{2}+2 \rho \theta\right) & , \quad 1 \leq t, s=0 \\ \rho E\left(v_{i t-1} v_{i t-1}\right)+\theta \sigma_{\varepsilon}^{2} & , \quad 2 \leq t, s=1 \\ \rho E\left(v_{i t-1} v_{i t-1}\right) & , \quad s+1 \leq t, 2 \leq s \leq T-1,\end{cases}
$$

where $\sigma_{\mu}^{2}=\operatorname{var}\left(\mu_{i}\right), \sigma_{\varepsilon}^{2}=\operatorname{var}\left(\varepsilon_{i t}\right)$ and $\sigma_{v_{0}}^{2}=\operatorname{var}\left(v_{i 0}\right)$ is the initial condition of the ARMA process. ${ }^{8}$

Three nested specifications of the model are estimated,

$$
(S 1)
$$

$$
u_{i t}=\mu_{i}+\varepsilon_{i t}
$$

\footnotetext{
${ }^{7}$ Estimation of such models either yielded permanent shocks of negligible magnitude or led to convergence problems.

${ }^{8}$ For the parameters of the ARMA-process to be estimable consistently, it is important to model this initial condition explicitly. See MaCurdy(1982), p. 93.
} 


$$
\begin{aligned}
& u_{i t}=\mu_{i}+\left[\rho v_{i t-1}+\theta \varepsilon_{i t-1}+\varepsilon_{i t}\right] \\
& u_{i t}=\alpha_{t} \mu_{i}+\lambda_{t}\left[\rho v_{i t-1}+\theta \varepsilon_{i t-1}+\varepsilon_{i t}\right]
\end{aligned}
$$

Specification (S1) is the canonical permanent/transitory model or random-effects model, the AR$\mathrm{MA}(1,1)$ process $(\mathrm{S} 2)$ allows for persistence in transitory shocks and the time shifters $\alpha_{t}$ and $\lambda_{t}$ in specification (S3) add the possibility of non-stationarities in the permanent or transitory component.

The parameters of the above models are estimated by Maximum Likelihood methods (see MaCurdy (1982)). This is in contrast to many recent studies (see e.g. Abowd/Card (1989), Moffitt/Gottschalk (1995), Baker (1997), Dickens (2000), Cappellari (2000), Ramos (2001) and Devicienti (2001)) which all use Chamberlain's (1984) Generalized Method of Moments procedure. The reason for using Maximum Likelihood is that this method makes it relatively easy to take into account the already mentioned non-independence of observations at the household level.

Due to the construction of the income variable and the use of household characteristics, stochastic variation is only independent between individuals who have not lived together in a household at any point during the sample period. This can be modelled by constructing clusters of individuals with the property that (i) individuals who have lived together during the sample period are in the same cluster and (ii) for individuals with the same cluster number who have not lived together during the sample period, there exists a sequence of individuals connecting the two individuals in which adjacent individuals have lived together at some point. (Property (ii) ensures that the clusters are minimal in a sense. ${ }^{9}$ ) Moreover, all of the following estimates make use of longitudinal sample weights $w_{i} .{ }^{10}$ Both clustering and sample weights can be taken into account for the estimation of covariances and standard errors by using methods developed for complex surveys (see e.g. Cochran (1977)).

As in MaCurdy (1982), a two-step estimation procedure is used. In a first step, the parameters $\beta_{t}$ are estimated by OLS separately for each period $t$. Selected results from these first-stage regressions are given in Table 1. The residuals from these regressions $\hat{u}_{i t}$ then form the basis for the estimation of the covariance structure. (MaCurdy (1982) shows that the asymptotic distribution of the estimates is not affected when the estimation procedure is split up into two steps). Autocovariances of order $k$ at time $t$

$$
\gamma_{t k}=E\left(u_{i t} u_{i t-k}\right)
$$

\footnotetext{
${ }^{9}$ The algorithm to generate such clusters from panel data is available from the author on request.

${ }^{10}$ These weights represent the inverse of the probability that an individual is included in the longitudinal sample. Their construction is based on models of the probability of leaving the panel in a given year and correct therefore to a certain extent for panel attrition (see Haisken-DeNew/Frick (2000), pp. 120 -133).
} 
can be estimated by

$$
\hat{\gamma}_{t k}=\frac{\sum_{i=1}^{N} w_{i}\left[\hat{u}_{i t} \hat{u}_{i t-k}\right]}{\sum_{i=1}^{N} w_{i}}
$$

with estimated variances

$$
\widehat{\operatorname{var}}\left(\hat{\gamma}_{t k}\right)=\frac{n_{c}}{n_{c-1}} \sum_{j=1}^{n_{c}}\left(r_{j}-\bar{r}\right)^{2}
$$

where

$$
r_{j}=\frac{\sum_{l \in C_{j}} w_{l}\left(\left[\hat{u}_{l t} \hat{u}_{l t-k}\right]-\hat{\gamma}_{t k}\right)}{\sum_{i=1}^{N} w_{i}},
$$

$\bar{r}=n_{c}^{-1} \sum_{j=1}^{n_{c}} r_{j}$ and $C_{j}, n_{c}$ denote the $j$-th cluster and the number of clusters, respectively. In the text, autocovariances are collected in a matrix $M=\left(\hat{\gamma}_{t k}\right)$. Note that $\hat{\gamma}_{t k}$ is the weighted mean of the variable $\left[\hat{u}_{i t} \hat{u}_{i t-k}\right]$ and that $\widehat{\operatorname{var}}\left(\hat{\gamma}_{t k}\right)$ is its estimated variance using survey methods (see e.g. Cochran (1977)).

For the estimation of the model parameters and their standard errors, MaCurdy's (1982) method is modified using the approach of Binder (1983) (also compare Skinner et al. (1989), pp. 80 - 83) to incorporate the sample weights and the clustering of observations. In terms of individual observations model (1)-(3) can be written as

$$
\left[\begin{array}{c}
y_{i 1} \\
y_{i 2} \\
\vdots \\
y_{i T}
\end{array}\right]=\left[\begin{array}{cccc}
x_{i 1}^{\prime} & & & \\
& x_{i 2}^{\prime} & & \\
& & \ddots & \\
& & & x_{i T}^{\prime}
\end{array}\right]\left[\begin{array}{c}
\beta_{1} \\
\beta_{2} \\
\vdots \\
\beta_{T}
\end{array}\right]+\left[\begin{array}{c}
u_{i 1} \\
u_{i 2} \\
\vdots \\
u_{i T}
\end{array}\right]
$$

or

$$
Y_{i}=X_{i} \beta+U_{i}
$$

with

$$
E\left(U_{i} U_{i}^{\prime}\right)=\Omega(\omega), \quad i=1 \ldots N,
$$

where the vector $\omega$ collects the parameters of the covariance matrix. Consistent estimates of $\omega$ can be obtained by maximizing the Pseudo-Log Likelihood function

$$
\begin{aligned}
P_{N}(\omega) & =\sum_{i=1}^{N} w_{i}\left[-\frac{1}{2} \log |\Omega(\omega)|-\frac{1}{2} \hat{U}_{i}^{\prime} \Omega(\omega)^{-1} \hat{U}_{i}\right] \\
& =\sum_{i=1}^{N} w_{i} P_{N, i}(\omega) .
\end{aligned}
$$

The first order conditions for this maximization problem are given by

$$
Q_{N}(\hat{\omega})=\sum_{i=1}^{N} w_{i} \frac{\partial P_{N, i}(\hat{\omega})}{\partial \hat{\omega}}=0 .
$$


A measure of the fit of the model is the sum of squared differences between the empirical moments and the theoretical moments implied by the model

$$
S S R=(\operatorname{vech}(\Omega(\hat{\omega}))-\operatorname{vech}(M))^{\prime}(\operatorname{vech}(\Omega(\hat{\omega}))-\operatorname{vech}(M))
$$

(The $\operatorname{vech}(\cdot)$ operator collects the distinct elements of the respective matrix.)

To estimate the variance-covariance matrix of $\hat{\omega}$, note that a Taylor-expansion of $Q_{N}(\hat{\omega})=0$ around the true value $\omega$ gives in the limit

$$
\operatorname{var}(\hat{\omega})=\left[\frac{\partial Q_{N}(\omega)}{\partial \omega}\right]^{-1} \operatorname{var}\left(Q_{N}(\omega)\right)\left[\frac{\partial Q_{N}(\omega)^{\prime}}{\partial \omega}\right]^{-1}
$$

which can be estimated by

$$
\widehat{\operatorname{var}}(\hat{\omega})=\left.\left[\frac{\partial Q_{N}(\omega)}{\partial \omega}\right]^{-1} \widehat{\operatorname{var}}\left(Q_{N}(\omega)\right)\left[\frac{\partial Q_{N}(\omega)^{\prime}}{\partial \omega}\right]^{-1}\right|_{\omega=\hat{\omega}}
$$

(compare eq. (22) in MaCurdy (1982)), where $Q_{N}(\omega)$ is regarded as the estimate of a population total whose variance can be estimated by survey methods, i.e.

$$
\widehat{\operatorname{var}}\left(Q_{N}(\omega)\right)=\frac{n_{c}}{n_{c}-1} \sum_{j=1}^{n_{c}}\left(z_{j}-\bar{z}\right)\left(z_{j}-\bar{z}\right)^{\prime}
$$

with

$$
z_{j}=\sum_{l \in C_{j}} w_{l} \frac{\partial P_{N, l}(\omega)}{\partial \omega}
$$

and $\bar{z}=n_{c}^{-1} \sum_{j=1}^{n_{c}} z_{j}$ (see Binder (1983), Skinner et al. (1989), p. 83 and Cochran (1977)).

If one assumes log-normality of incomes, model (1)-(3) represents a fully specified intertemporal model of the income distribution with explicit implications for poverty, inequality and income mobility. ${ }^{11}$ For example, the poverty rate for individuals with characteristics $x_{i t}$ can be calculated as

$$
P_{t}^{1}=P\left(y_{i t} \leq Z_{t}^{1}\right)=P\left(\frac{u_{i t}}{\sqrt{\operatorname{var}\left(u_{t}\right)}} \leq \frac{Z_{t}^{1}-x_{i t}^{\prime} \beta_{t}}{\sqrt{\operatorname{var}\left(u_{t}\right)}}\right)=\Phi\left(\frac{Z_{t}^{1}-x_{i t}^{\prime} \beta_{t}}{\sqrt{\operatorname{var}\left(u_{t}\right)}}\right)
$$

for a given poverty line $Z_{t}^{1}$, where $\Phi(\cdot)$ denotes the normal distribution function. If the income distribution is partitioned into four income classes, the 'poor', the 'lower middle class', the 'upper middle class' and the 'rich', the proportion of individuals with characteristics $x_{i t}$ who belong to the 'lower middle class', the 'upper middle class' and the 'rich' is given by

$$
\left.P_{t}^{2}=P\left(Z_{t}^{1} \leq y_{i t} \leq Z_{t}^{2}\right)=\Phi\left(\frac{Z_{t}^{2}-x_{i t}^{\prime} \beta_{t}}{\sqrt{\operatorname{var}\left(u_{t}\right)}}\right)\right)-\Phi\left(\frac{Z_{t}^{1}-x_{i t}^{\prime} \beta_{t}}{\sqrt{\operatorname{var}\left(u_{t}\right)}}\right)
$$

\footnotetext{
${ }^{11}$ The following builds on Lillard/Willis (1978), but extends their analysis of low income states to other parts of the distribution.
} 


$$
\begin{aligned}
& \left.P_{t}^{3}=P\left(Z_{t}^{3} \leq y_{i t} \leq Z_{t}^{2}\right)=\Phi\left(\frac{Z_{t}^{3}-x_{i t}^{\prime} \beta_{t}}{\sqrt{\operatorname{var}\left(u_{t}\right)}}\right)\right)-\Phi\left(\frac{Z_{t}^{2}-x_{i t}^{\prime} \beta_{t}}{\sqrt{\operatorname{var}\left(u_{t}\right)}}\right) \\
& P_{t}^{4}=P\left(Z_{t}^{3} \leq y_{i t}\right)=1-\Phi\left(\frac{Z_{t}^{3}-x_{i t}^{\prime} \beta_{t}}{\sqrt{\operatorname{var}\left(u_{t}\right)}}\right) .
\end{aligned}
$$

In this paper, the points $Z_{t}^{1}, Z_{t}^{2}$ and $Z_{t}^{3}$ are specified as $0.5,1$ and 1.5 times contemporaneous mean income of the respective sample. (This kind of partition of the German income distribution is motivated by Schluter (1998), p.159.) Note that the sample-dependent definition of $Z_{t}^{1}, Z_{t}^{2}$ and $Z_{t}^{3}$ means, for example, that separate poverty lines for East and West Germany are used. It should be pointed out that this notion of 'poverty' is completely relative. In particular, it implies that 'poverty' may stay constant even if living standards are generally rising.

If one is interested in the income position of an individual with characteristics $x_{i t}$ in the long run, i.e. abstracting from transitory shocks (and assuming that the weight $\alpha_{t}$ does not change), one can carry out similar calculations based on permanent income

$$
y_{i t}^{P}=x_{i t}^{\prime} \beta_{t}+\alpha_{t} \mu_{i}
$$

instead of actual income $y_{i t}$. The share of individuals with characteristics $x_{i t}$ whose permanent income lies in the respective income class is then given by

$$
\begin{aligned}
& \left.P_{t}^{1, p}=\Phi\left(\frac{Z_{t}^{1}-x_{i t}^{\prime} \beta_{t}}{\sqrt{\operatorname{var}\left(\alpha_{t} \mu_{i}\right)}}\right)\right) \\
& \left.P_{t}^{2, p}=\Phi\left(\frac{Z_{t}^{2}-x_{i t}^{\prime} \beta_{t}}{\sqrt{\operatorname{var}\left(\alpha_{t} \mu_{i}\right)}}\right)\right)-\Phi\left(\frac{Z_{t}^{1}-x_{i t}^{\prime} \beta_{t}}{\sqrt{\operatorname{var}\left(\alpha_{t} \mu_{i}\right)}}\right) \\
& \left.P_{t}^{3, p}=\Phi\left(\frac{Z_{t}^{3}-x_{i t}^{\prime} \beta_{t}}{\sqrt{\operatorname{var}\left(\alpha_{t} \mu_{i}\right)}}\right)\right)-\Phi\left(\frac{Z_{t}^{2}-x_{i t}^{\prime} \beta_{t}}{\sqrt{\operatorname{var}\left(\alpha_{t} \mu_{i}\right)}}\right) \\
& P_{t}^{4, p}=1-\Phi\left(\frac{Z_{t}^{3}-x_{i t}^{\prime} \beta_{t}}{\sqrt{\operatorname{var}\left(\alpha_{t} \mu_{i}\right)}}\right) .
\end{aligned}
$$

The evolution of income inequality is described by the sequence of period variances of log income $\operatorname{var}\left(y_{i t}\right)$. The share of inequality that is due to permanent rather than transitory income differences is given by

$$
s_{t}=\alpha_{t}^{2} \sigma_{\mu}^{2} / \operatorname{var}\left(u_{i t}\right)
$$

Similar implications can be derived for income mobility. The joint probability of being poor in period $t$ and being poor in period $t-s$ for an individual with characteristics $x_{i t}$ can be expressed as

$$
P_{t, t-s}^{1,1}=P\left(y_{i t} \leq Z_{t}^{1}, y_{i t-s} \leq Z_{t-s}^{1}\right)=\Phi\left(\frac{Z_{t}^{1}-x_{i t}^{\prime} \beta_{t}}{\sqrt{\operatorname{var}\left(u_{i t}\right)}}, \frac{Z_{t-s}^{1}-x_{i t-s}^{\prime} \beta_{t-s}}{\sqrt{\operatorname{var}\left(u_{i t-s}\right)}}, \xi^{t, t-s}\right)
$$


where

$$
\xi^{t, t-s}=\frac{\operatorname{cov}\left(u_{i t}, u_{i t-s}\right)}{\sqrt{\operatorname{var}\left(u_{i t}\right) \operatorname{var}\left(u_{i t-s}\right)}}
$$

is the correlation of incomes between period $t$ and $t-s$ and $\Phi(\cdot, \cdot, \cdot)$ is the distribution function of the bivariate normal distribution. Analogous expressions can be found for the joint probability of being in income class $m \in\{2,3\}$ in periods $t$ and $t-s$

$$
\begin{aligned}
P_{t, t-s}^{m, m}= & P\left(Z_{t}^{m-1} \leq y_{i t} \leq Z_{t}^{m}, Z_{t-s}^{m-1} \leq y_{i t-s} \leq Z_{t-s}^{m}\right) \\
= & \Phi\left(\frac{Z_{t}^{m}-x_{i t}^{\prime} \beta_{t}}{\sqrt{\operatorname{var}\left(u_{i t}\right)}}, \frac{Z_{t-s}^{m}-x_{i t-s}^{\prime} \beta_{t-s}}{\sqrt{\operatorname{var}\left(u_{i t-s}\right)}}, \xi^{t, t-s}\right)-\Phi\left(\frac{Z_{t}^{m}-x_{i t}^{\prime} \beta_{t}}{\sqrt{\operatorname{var}\left(u_{i t}\right)}}, \frac{Z_{t-s}^{m-1}-x_{i t-s}^{\prime} \beta_{t-s}}{\sqrt{\operatorname{var}\left(u_{i t-s}\right)}}, \xi^{t, t-s}\right) \\
& -\Phi\left(\frac{Z_{t}^{m-1}-x_{i t}^{\prime} \beta_{t}}{\sqrt{\operatorname{var}\left(u_{i t}\right)}}, \frac{Z_{t-s}^{m}-x_{i t-s}^{\prime} \beta_{t-s}}{\sqrt{\operatorname{var}\left(u_{i t-s}\right)}}, \xi^{t, t-s}\right)+\Phi\left(\frac{Z_{t}^{m-1}-x_{i t}^{\prime} \beta_{t}}{\sqrt{\operatorname{var}\left(u_{i t}\right)}}, \frac{Z_{t-s}^{m-1}-x_{i t-s}^{\prime} \beta_{t-s}}{\sqrt{\operatorname{var}\left(u_{i t-s}\right)}}, \xi^{t, t-s}\right)
\end{aligned}
$$

and of belonging to the richest income class in both $t$ and $t-s$

$$
\begin{aligned}
P_{t, t-s}^{4,4} & =P\left(Z_{t}^{3} \leq y_{i t}, Z_{t-s}^{3} \leq y_{i t-s}\right) \\
& \left.\left.=1-\Phi\left(\frac{Z_{t}^{3}-x_{i t}^{\prime} \beta_{t}}{\sqrt{\operatorname{var}\left(u_{t}\right)}}\right)\right)-\Phi\left(\frac{Z_{t-s}^{3}-x_{i t-s}^{\prime} \beta_{t-s}}{\sqrt{\operatorname{var}\left(u_{t-s}\right)}}\right)\right)+\Phi\left(\frac{Z_{t}^{3}-x_{i t}^{\prime} \beta_{t}}{\sqrt{\operatorname{var}\left(u_{i t}\right)}}, \frac{Z_{t-s}^{3}-x_{i t-s}^{\prime} \beta_{t-s}}{\sqrt{\operatorname{var}\left(u_{i t-s}\right)}}, \xi^{t, t-s}\right) .
\end{aligned}
$$

These joint probabilities can be used to calculate (one-period) staying probabilities

$$
P_{t, t-1}^{m \mid m}=\frac{P_{t, t-1}^{m, m}}{P_{t-1}^{m}}
$$

for income states $m=1 \ldots 4$, the poverty exit rate

$$
E_{t}=1-P_{t, t-1}^{1 \mid 1}
$$

and a mobility measure based on staying probabilities, the Prais index

$$
M_{t, t-1}=\left(4-\sum P_{t, t-1}^{m \mid m}\right) / 3
$$

As an illustration of how shock persistence $\rho$ and individual heterogeneity $\left(\sigma_{\mu}^{2}>0\right)$ affect the structure of serial correlation, consider the case where the permanent and transitory components are stationary $\left(\alpha_{t} \equiv \lambda_{t} \equiv 1\right)$ and no moving average part is present $(\theta=0)$. Then the correlation of incomes is

$$
\xi^{t, t-s}=\frac{\sigma_{\mu}^{2}}{\operatorname{var}\left(u_{i t}\right)}+\frac{\operatorname{var}\left(u_{i t}\right)-\sigma_{\mu}^{2}}{\operatorname{var}\left(u_{i t}\right)} \rho^{s} .
$$

Clearly, in the case of a given individual (i.e. $\sigma_{\mu}^{2}=0$ ) and no shock persistence $(\rho=0)$, incomes are serially uncorrelated $\left(\xi^{t, t-s}=0\right)$. In the case of a given individual $\left(\sigma_{\mu}^{2}=0\right)$ and positive shock persistence, serial correlation is a decaying function of the shock persistence parameter only, i.e. 
$\xi^{t, t-s}=\rho^{s}$. On the other hand, even in the case without shock persistence, serial correlation can be positive, if one is dealing with a randomly drawn individual from a heterogenous population $\left(\sigma_{\mu}^{2}>0\right)$. In that case, $\xi^{t, t-s}=\sigma_{\mu}^{2} / \operatorname{var}\left(u_{i t}\right)>0$. Note that, in the presence of shock persistence and population heterogeneity, the value of the information about the state occupied in $t-s$ gets smaller and smaller, but never reaches zero because serial correlation through individual-specific unobservables is always present. To see this, note that $P_{t, t-s}^{m, m}>P_{t}^{m} P_{t-s}^{m}$ whenever $\xi^{t, t-s}>0$, so that $P_{t, t-s}^{m \mid m}=P_{t, t-s}^{m, m} / P_{t-s}^{m}>$ $P_{t}^{m} P_{t-s}^{m} / P_{t-s}^{m}=P_{t}^{m}$.

\section{Empirical results}

\subsection{West Germany 1990 - 1998}

The first subsample studied here is that for West Germany 1990 to 1998. West Germany has a population size about four times larger than East Germany's. As a consequence of a well-developed welfare state and the strong position of trade unions in the labor market, West Germany is often seen as an example of a country with a very stable income distribution. The question is to what extent this is reflected in the covariance structure of equivalent incomes. The empirical variance covariance matrices for the west German sample are shown in Figures 1 and 2 (also compare Tables 2 and 3). In the case without covariates, both variances and autocovariances were more or less stationary. There was a slight peak in variance in 1994 and two not very pronounced troughs, one in 1991/92 and another one in 1996/97. First order autocovariances slightly peaked in 1994, but were generally also quite stable during the period under consideration.

- Figure 1 about here -

- Figure 2 about here -

Figure 2 shows the corresponding variances and covariances after observed characteristics have been controlled for. The results are very similar, except that numbers are much smaller in magnitude. By controlling for characteristics such as the age, education and employment structure of the individual's household, residual variance is reduced to 62 to 68 percent of its original magnitude, indicating that about 32 to 38 percent of income inequality is explained by differences in these characteristics. Similarly, between 51 and 57 percent of first order autocovariance remains after observed characteristics are controlled for, implying that serial correlation in these characteristics explain between 43 and 
49 percent of the income covariance between successive periods. In both Figures 1 and 2, a big drop in autocovariance for the first lag and slowly declining autocovariances after that suggest an $\operatorname{ARMA}(1,1)$ process with a negative moving average part.

— Table 2 about here -

— Table 3 about here -

Table 4 gives the parameter estimates for different specifications of the model. In the case without covariates, fitting the canonical permanent/transitory model (column 1) yields a permanent variance of 0.1274 and a transitory variance of 0.0541 , indicating that 70 percent of differences in equivalent income were of a permanent nature and 30 percent were purely transitory. Permanent variance is reduced by 20 percent to 0.1000 if an $\operatorname{ARMA}(1,1)$ process is estimated (column 2)), which allows for serially correlated transitory shocks. In this case, the estimate for the autoregressive part is $\rho=0.7403$ and that of the moving average part $\theta=-0.2967$. Note that the latter is negative as expected. The sum of squared residuals (second but last number in column 2) and the Wald-statistic (last number in column 2) show that the $\operatorname{ARMA}(1,1)$ process fits the data much better than the simple permanent/transitory model and that the restrictions implied by the latter are rejected within the ARMA $(1,1)$ model.

- Table 4 about here -

If an $\operatorname{ARMA}(1,1)$ process with time shifters $\alpha_{t}$ and $\lambda_{t}$ is fitted (column 3), the estimate for the serial correlation coefficient $\rho$ and the moving average part are reduced and non-stationarities in the permanent and the transitory component are picked up. The estimate for the serial correlation coefficient is $\rho=0.3581$ and that for the moving average part $\theta=-0.279$. These estimates imply that a transitory shock in equivalent income was reduced to a mere 8 percent after one period and to one percent after three periods. This means that in West Germany, the effects of transitory income shocks tended to vanish very quickly.

Controlling for personal characteristics in the simplest specification (see column 4) reduces the variance of the permanent component from 0.1274 to 0.0705 . This considerable reduction by almost 50 percent shows that a large share of permanent differences between individuals was due to permanent differences in the age, education and employment structure of their households, although differences in unobserved characteristics were equally important. In contrast to the variance of the permanent component, the size of the transitory component stayed about the same, indicating that this part 
of individual heterogeneity was entirely due to unobserved characteristics. As a consequence, the share of the permanent component in overall variance was reduced by 10 percentage points, from 70 to 60 percent. If the simple $\operatorname{ARMA}(1,1)$ process is fitted to the data with covariates (column $5)$, the autoregressive parameter falls from 0.7403 to 0.6265 , suggesting that serial correlation in observed variables picked up some of the persistence of transitory shocks. Fitting the ARMA $(1,1)$ with time shifters (see column 6) picks up period-specific effects and further reduces the estimate of the autocorrelation coefficient $\rho$.

Figure 3 shows the evolution of the time shifters $\alpha_{t}$ and $\lambda_{t}$ for the case without and for the one with covariates. The graph suggests that transitory shocks gained importance over the nineties, while the importance of the permanent component reached a slight peak in 1992, but generally remained stable. In the case without covariates, the share of income inequality due to permanent differences between individuals rose from about 59 percent in 1990 to almost 70 percent in 1992, after which it slowly fell back to a level near 52 percent (see column 3 of Table 4). The results for the time-varying weights in the case with covariates are very similar to the case without covariates, although the Waldstatistic (see last line in column 6 of Table 4) was too small to reject the null hypothesis that all these weights were equal to one. Taken together, the results indicate that income inequality in West Germany got less persistent in recent years, because transitory income shocks increased in size.

- Figure 3 about here -

The standard errors in Table 4 show that all parameters except the initial variances were significantly different from zero at the 5 percent level. In the case without covariates (see column 3 ), the estimates for the time-shifters $\alpha_{t}$ and $\lambda_{t}$ were jointly different from one but not individually. In the case with covariates (column 6), they were neither jointly nor individually different from one.

It is interesting to compare these inferences with the case in which standard errors are based on the false assumption of independent observations. The numbers in Table A1 in the appendix show that this leads to too low standard errors. In some cases, the wrong standard errors suggested statistical significance where there was none. For example, the estimates of $\lambda_{1994}$ to $\lambda_{1998}$ in column 3 were individually different from one if the wrong standard errors were used, but this was not the case if the clustering of observations was taken into account. In general, standard errors based on the independence assumptions were between 11 and 28 percent (20 percent on average) too low when compared to those based on clustering. Similarly, with a p-value of 0.0004, the Wald-statistic in the case with covariates (last line of column 6 in Table A1) indicates that the time shifters were jointly different from one at conventional significance levels, whereas a p-value of 0.0689 suggests the opposite 
if the Wald-test is based on an appropriate estimate of the variance covariance matrix of the parameters (last line of column 6 in Table 4).

What do the parameter estimates imply for poverty and other income states? Table 5 shows the population shares of the different income classes defined in the previous section. All numbers in this table were derived from the parameter estimates of the most general specification given in Table 4 . In 1990, 9 percent of the population was poor, 50 and 29 percent belonged to one of the middle classes and 12 percent could be characterized as being 'rich'. ${ }^{12}$

Columns 5 to 8 of Table 5 show the population shares based on permanent rather than actual income. The numbers suggest that the long-term risk of being poor was much lower than the corresponding short-term risk (4 compared to 9 percent). The share of people whose permanent income lay in one of the middle income classes was 58 and 32 percent, whereas 7 percent of the population belonged to the 'rich' in the long-term. The last four columns of Table 5 give the ratio of long-term to short-term rates, indicating that only 43 percent of the people who were poor in one period were expected to be poor in the long term. Similarly, the chance of belonging to the top income class in the short term was twice as high as in the long term, while individuals in the middle classes were more likely to be there in the long run than in the short run.

- Table 5 about here -

Table 5 also shows poverty rates and population shares for selected subpopulations. The question is to what extent hypotheses about the well-being of particular population subgroups such as lone mothers, 'double income no kids' households, couples with children or pensioner households are confirmed or rejected by empirical results.

Lone parents, and in particular lone mothers, are generally seen as being particularly vulnerable to poverty. This is confirmed by the results given in rows 4 to 8 of Table 5 . Among members of the typical lone mother household consisting of a single mother and a child aged 0-6 years, over 25 percent were poor. In general, individuals from lone mother households clearly belonged to one of the two bottom income classes. Poverty rates were particularly high among non-employed lone mothers with three children and among unemployed mothers with two children (43 and 44 percent). By comparison, childless single men faced much lower poverty rates (4 percent), and a considerable proportion of these individuals were 'rich'.

\footnotetext{
${ }^{12}$ The corresponding non-parametric estimates were $7,53,29$ and 11 percent.
} 
Persistent poverty could be a problem for lone mothers, especially if they had many children or were unemployed. ${ }^{13}$ For these groups, the risk of being poor in the long term was almost as high as the risk of being poor in a given period. By contrast, only 14 percent of childless single men who were poor in one period were expected to be poor in the long run and almost one third of the short-term 'rich' in this group were 'rich' in the long term.

At the other end of the spectrum, there are 'double income no kids' households. These households are expected to be very well off, as they have double earnings and no children to take care of. Again, this hypothesis is confirmed by the results given in Table 5. Almost no individuals in 'double income no kids' households suffered from poverty. But even if children were present, these households were practically immune to poverty. The only case where the poverty rate approached the population average (9 percent) was if one of the persons became unemployed. Particularly well off were couples where both partners had high qualifications. Seventy seven percent of these individuals were 'rich' and another 22 percent belonged to the upper middle class of incomes. Couples with double income aged 42 to 64 years were also very well off, 43 percent of which had incomes in the upper middle range. With regard to permanent income, 'double income no kids' households were clearly concentrated in the middle and the top range of incomes. No-one in this subgroup suffered from long-term poverty. Even in the case of one unemployed household member, only 28 percent of those currently poor were expected to be poor in the longer run.

Due to their large population share, the situation of couples with children is of particular interest. The poverty rates of these individuals were generally higher than the population average (13 to 18 percent), except in the cases where the only earner in the household was high-skilled or where both adults were employed (3 to 4 percent). Non-German nationality and low qualifications of the earner led to higher poverty risks. Unemployment in the household increased poverty rates to over 40 percent. The proportion of individuals from couple with children households in the upper income classes was practically zero, except in the cases where the earner was high-skilled or where both adults were employed (13 and 10 percent). For some couples with children poverty was a long-term phenomenon, especially if the household was affected by unemployment. In this case, a considerable 38 percent of this subpopulation were long-term poor.

The discussion about 'old age poverty' suggests that pensioners face above-average poverty risks. However, this is not confirmed by the data. On the contrary, individuals in the reference pensioner household had a relatively low poverty risk ( 5 percent). This rate was high (25 percent) only if the pensioner in question had low qualifications, while pensioners with high qualifications had poverty rates of zero and over two thirds of this subgroup belonged to the 'rich' group. With poverty rates of 8

${ }^{13}$ Note that such a statement assumes fixed characteristics over time. 
percent, single male pensioners were slightly better off than their female counterparts who experienced rates near the population average (10 percent). The differential between low-skilled and high-skilled pensioners was also apparent in permanent poverty rates. Otherwise, most pensioners populated the middle range of incomes in the short and in the long run.

The second half of Table 5 shows the corresponding results for 1998. They suggest that poverty slightly decreased between 1990 and 1998, from 9 to 7 percent. Similarly, the long-term probability of belonging to the poor or the 'rich' income class decreased slightly, concentrating permanent incomes more at the center of the distribution. Poverty in different subgroups also tended to be lower, but relative incomes did not change much. The notable exception were lone mother households with two or more children and low-skilled pensioners. For these households, poverty risks decreased disproportionately.

Table 6 displays a number of mobility measures for the transition 1990 to 1991. The probability of staying in the bottom, the upper middle or the top income class was approximately one half $(0.466$, 0.504 and 0.535$)$. This means that individuals in these income classes were expected to stay there roughly 2 periods. The staying probability for individuals in the lower middle class was higher (0.713), implying an expected staying time of 3.48 periods. The poverty exit rate (column 5) shows that over fifty percent of the poor were able to escape poverty in a given period. The last column of the table reports the Prais index of overall mobility. It can be interpreted as a kind of average over the probabilities of exiting the different income classes and had the value 0.594 for a randomly drawn individual.

— Table 6 about here -

Table 6 also gives some mobility results for selected population subgroups. Lone mothers had high staying probabilities at the bottom of the distribution and low staying probabilities at the top. Poverty exit rates for lone mothers were particularly low if the lone mother had three children or if she was unemployed (21 and 29 percent). For these two subgroups, the Prais mobility index was higher than average because the extremely high exit probabilities for the upper range of the distribution were not fully compensated by low exit probabilities at the bottom.

By contrast, 'double income no kids' households had very low staying probabilities at the bottom of the distribution and high staying probabilities at the top. Overall mobility for these individuals was around 0.70. An exception was households with two high-skilled earners for which it was almost 0.76.

The numbers for couples with children were not so different from the population average, but staying probabilities in the upper part of the distribution were lower. Despite considerable heterogenei- 
ty in this group - the staying probabilities in the lowest income class varied from 0.291 for households in which the earner is high-skilled to 0.608 in households where the earner is unemployed - mobility indices were very similar. The reason is that low staying probabilities at one end of the distribution were usually offset by high staying probabilities at the other end. In the case of couples with children, this led to an almost uniform mobility index of 0.703 to 0.729 .

Pensioners generally had lower-than-average staying probabilities at the bottom and higher-thanaverage staying probabilities at the top. Pensioner couples with high qualifications had an extremely high chance of escaping low income (almost 90 percent), reflecting the low unconditional poverty rate of this kind of household.

The second half of Table 6 shows that mobility during the transition 1990/91 did not differ dramatically from mobility during the transition 1997/98. On average, staying probabilities were slightly higher in all income classes, leading to a lower index of overall mobility. An exception was the poverty persistence of lone mothers with two or more children which fell from 0.793 to 0.603 for nonemployed lone mothers with three children and from 0.537 to 0.393 for employed lone mothers with two children. As in 1990/91, mobility indices in 1997/98 were very similar across different subpopulations, albeit on a lower level than in 1990/91.

\subsection{East Germany 1990 to 1998}

How does this relatively static picture of the west German income distribution compare with the experience of East Germany? East Germany was reunified with West Germany in fall 1990. Reunification meant that the west German political and economic system was extended to the eastern part of the country. It is well known that this transition had a large impact on the east German income distribution. ${ }^{14}$ This is reflected in Figures 4 and 5 (also compare Tables 7 and 8) which show the empirical variances and covariances for the east German sample 1990 to 1998.

In the case where covariates are not controlled for (Figure 4), variance increased steeply from 1990 to 1991 and then stayed constant until 1995. In 1996, it fell slightly and then remained more or less constant for the rest of the sample period. The decrease in inequality in 1996 was preceded by a sharp decline in east German GDP growth rates which set in when the so-called reunification boom came to an end in 1994. Figure 4 also suggests that first and higher order covariances were non-stationary during that time, with a clearly rising tendency until 1994. It should be noted that despite the rise at the beginning of the nineties, inequality in East Germany was much lower than in

\footnotetext{
${ }^{14}$ See for example Hauser/Wagner (1996), Burda/Schmidt (1997) or Biewen (2001).
} 
West Germany during the whole sample period.

- Figure 4 about here -

- Figure 5 about here -

It is interesting to see that in the case with covariates (Figure 5), the rise in variance in 1990/91 was immediately followed by a drop in 1992 and in 1993. The variance then rose again in 1994 and 1995 and stayed more or less constant until the end of the sample. A possible explanation is that the fall in inequality in 1992 and 1993 is the consequence of controlling for inequality increasing factors such as rising unemployment and falling labor market participation. It is known that much of the initial increase in inequality was caused by a sudden rise in wage inequality - which was concentrated almost exclusively in the transition year $1990^{15}$-, but also by increasing unemployment and falling labor market participation, especially of women. ${ }^{16}$ However, unemployment kept rising until 1993, after which it stabilized and even fell for younger people. Similarly, participation of persons aged between 42 to 64 year fell until 1993, picked up for a short time and stayed constant after 1995. As unemployment and falling participation are generally regarded as inequality increasing, controlling for these factors led to a lower level of measured inequality. Taken together, Figures 4 and 5 suggest that differences in observables explain between 35 and 52 percent of inequality, which is slightly more than in West Germany (32 to 38 percent).

— Table 7 about here -

— Table 8 about here -

The estimates for the model parameters given in Table 9 show that the permanent variance in East Germany was much lower than in the West, but that the transitory component was more persistent. For example, in the case with time shifters and no covariates (column 3), the coefficients imply that a period-specific income shock was reduced to 38 percent after one period ( 8 percent in West Germany). After three periods, about 16 percent of the initial shock remained (compared to one percent in West Germany).

— Table 9 about here -

\footnotetext{
${ }^{15}$ See Hauser/Wagner(1996), Table 5.

${ }^{16}$ See Biewen (2001).
} 
Figure 6 shows the evolution of the time shifters $\alpha_{t}$ and $\lambda_{t}$ (also compare Table 9, columns 3 and 6). The importance of the permanent component increased considerably after 1990, while that of the transitory part slightly fell. The likely explanation for the remarkable rise of the permanent component is the enormous wage growth in East Germany between 1990 and 1998. In the years following reunification, trade unions in East Germany tried to push through the same wages as in the West, with the result that wages almost doubled between 1990 and 1998. As many of the unobserved characteristics underlying wages - e.g. skill, motivation or working hours - are time invariant for many individuals, the growth in wages increased existing wage differentials induced by persistent differences in these characteristics.

\section{— Figure 6 about here -}

In the case without covariates, the share of the permanent component increased from 20 percent in 1990 to 72 percent in 1998 (see column 3 of Table 9), indicating that income inequality got more and more persistent towards the end of the nineties. This can be interpreted as convergence to western conditions, although in 1998, the share of the permanent component already exceeded the one in West Germany (72 percent compared to 52 percent). The results for the case with covariates are very similar and show that the observed pattern was driven by unobservables. In both the case without and the one with covariates, most of the $\alpha_{t}$ 's but not all of the $\lambda_{t}$ were significantly different from one. This and the fact that a joint test rejects the hypothesis that all the time shifters were equal to one, corroborates the finding that the east German distribution of the nineties was characterized to a large extent by non-stationarity.

What do the estimates imply for the distribution of different household types over the income range? Table 10 shows that incomes in East Germany were much more compressed around the center of the distribution than in West Germany. In 1990, only 3 percent of the population suffered from poverty and only 9 percent were 'rich'. This concentration at the center of the distribution was even more pronounced for permanent income. Virtually nobody's permanent income fell below the poverty line or exceeded the line that defines the income of the 'rich'.

\section{- Table 10 about here -}

As in West Germany, in 1990 most lone mother households belonged to the lower middle class of incomes. Partly in contrast to the west German situation, non-employed lone mothers with their children suffered from very high poverty risks. In extreme cases more than fifty percent of them were poor. Unemployment was less of a risk factor at that time as long-term unemployment was still low 
and unemployment benefits were more generous than after reunification. The poverty rate for single men was only 3 percent. With regard to long-term income, most lone mothers and single men belonged almost certainly to the lower middle class of incomes. Exceptions were non-employed lone mothers who were the only group with a risk of being permanently poor.

Similar to West Germany, 'double income no kids' couples were very well off and faced no risk of poverty at all, neither in the short nor in the long term.

Most east German couples with children faced in 1990 poverty rates above the east German average but below the rates for similar cases in West Germany. For example, if the breadwinner in a couple with children household was unemployed, this led to a poverty risk of 13 percent in East Germany, compared to 41 percent in the West. Despite non-negligible poverty risks for some subgroups, poverty was a very transitory phenomenon for these households. In the longer run, east German couples with children belonged almost certainly to the lower middle class of incomes.

Partly in contrast to West Germany, single or low-skilled pensioners in the East faced considerable poverty rates (15 and 37 percent). In view of the egalitarian income policy under the socialist regime, this finding is quite remarkable. Similar to lone parents households and couples with children, most pensioners did not reach into the upper parts of the distribution, neither in the short nor in the long term.

How had these figures changed eight years after reunification? The overall distribution of contemporaneous incomes over the four income classes did not change very much between 1990 and 1998 (see second half of Table 10). The poverty rate was almost the same (4 percent compared to 3 percent in 1990) and the shares of the other three brackets did not change by more than one percentage point. However, the distribution of permanent incomes had widened considerably, reflecting its increased share in overall variance (see columns 5 to 8 of Table 10).

Despite the almost unchanged overall distribution of actual income, some subgroups had altered their position in the distribution. For example, poverty rates for non-employed lone mothers went down considerably. Non-employed lone mothers with one child now faced poverty risks of 17 percent, compared to 45 percent in 1990. The poverty rate was even lower if the non-employed lone mother had moved to West Germany (6 percent instead of 16 percent). The numbers also suggest that the poverty increasing effect of a high number of children had diminished, an experience shared by West Germany.

By contrast, unemployment had become a major poverty risk. The poverty rate for unemployed lone mothers with 2 children went up from 13 percent in 1990 to 42 percent in 1998 . The reason is that, 
compared to 1990, unemployment in 1998 often meant long-term unemployment with correspondingly low unemployment benefits. Moreover, replacement rates were generally lower in 1998 than in the short non-socialist period before reunification. In 1998, long term poverty was particularly a problem for lone mothers with many children or the ones affected by unemployment. For these groups, 87 and 91 percent of the short-term poor were also expected to be poor in the long run.

In contrast to lone mothers, the picture for 'double income no kids' households did not change dramatically between 1990 and 1998. However, poverty of couples with children slightly fell from 9 to 7 percent and to 2 percent if the family had moved to the West. Similar to lone mother households, couples with children faced high poverty rates of over 30 percent if the breadwinner was unemployed. Unemployment also increased the risk of long-term poverty considerably.

It is well known that east German pensioners experienced a dramatic shift up the income distribution in the years after reunification. Due to full employment under socialism they had long, uninterrupted employment histories which secured them high pensions under the west German earningsrelated pensions system. The poverty rate for the typical two pensioner household fell from 9 to 2 percent, which was far below average. The income boost for pensioners was also reflected in the numbers for permanent income. In 1990, the typical pensioner household almost surely belonged to the lower middle class of incomes, whereas in 1998, this subpopulation was evenly divided between the lower and the upper middle class of permanent incomes.

The mobility measures for east Germany shown in Table 11 indicate that income persistence was initially lower than in West Germany. Staying probabilities were smaller and overall mobility higher. Over 69 percent of the poor were expected to escape poverty after one period (compared to 53 percent in West Germany), which implies that individuals stayed in poverty for 1.45 periods on average. Persistently low income, i.e. low poverty exit rates, was in particular a problem for unemployed lone mothers and for non-employed lone mothers with many children (exit rates of 33 and 51 percent). 'Double income no kids' households were characterized by high exit rates at the bottom and high staying probabilities at the top. East German couples with children were more likely to stay at the bottom than at the top end of the distribution, although poverty exit rates differed considerably across household types. Pensioners generally had high poverty exit rates and high staying probabilities in the two middle income classes.

As in West Germany, mobility indices showed little variation across population subgroups because low staying probabilities at the bottom were usually compensated by high staying probabilities at the top and vice versa.

- Table 11 about here - 
By 1998, the mobility behaviour of east Germans had become more similar to that of West Germans. In particular, staying probabilities for the bottom and the two upper income class moved to values near 0.5 as in West Germany, while that for the lower middle class increased to 0.724 (which is almost identical to the west German figure of 0.746). Convergence was not complete however, and the index measuring overall mobility remained higher than in the West (0.589 compared to 0.521). The decline in east German income mobility reflects the increasing weight of the permanent component documented in Table 9 (columns 3 and 6).

\subsection{West Germany 1984 to 1990}

This section briefly discusses the long-term stability of the west German covariance structure. ${ }^{17}$ The results for the additional west German sample show that income inequality was more or less stationary between 1984 and 1990. The parameter estimates suggest that the variance of the income innovations $\sigma_{\varepsilon}^{2}$ was larger and that transitory shocks were slightly more persistent in the eighties than in the nineties. This resulted in a lower contribution of the permanent component to overall variance (about 10 to 20 percent lower).

Moreover, some subgroups had different relative positions than in the nineties. For example, the poverty rate of non-employed lone mothers with 3 children used to be higher in 1984 (60 percent compared to 43 percent in 1990). Similarly, 'double income no kids' couples were even better off in 1984 than in 1990, confirming the image of the eighties as the 'yuppie' decade. Pensioners also had a more favourable relative position in 1984 than in both 1990 and 1998. However, taken together, the estimates for the additional sample suggest that the west German income distribution of the eighties did not differ substantially from that in the nineties.

\section{$5 \quad$ Summary and concluding remarks}

This paper studied the persistence of poverty and inequality in Germany within the framework of a covariance structure model. The empirical results can be summarized as follows.

In West Germany, the income distribution seemed fairly stationary during the nineties, with two hardly noticeable troughs in inequality in 1991 and 1997. During this period, permanent differences between individuals accounted for 50 to 70 percent of total inequality. The rest of overall inequality

\footnotetext{
${ }^{17}$ No tables will be presented but all results are available from the author on request.
} 
was due to transitory shocks that did not persist for more than one or two periods. The average duration of a poverty spell was 2 years.

Characteristics such as the age, education and employment structure of the individual's household explained between 32 and 38 percent of total inequality. In the period under investigation, lone mothers and couples with children were more likely to populate the lower parts of the income distribution, while 'double income no kids' households and pensioners were more likely to be found in the upper parts. The characteristics that were most closely associated with low income status were unemployment and a large number of children, although the latter relationship seemed weaker in 1998 than in 1990. On the other hand, the presence of two earners and/or high qualifications almost certainly put households in one of the upper income classes.

Permanent incomes were more concentrated at the center of the distribution than contemporaneous incomes, implying that individuals who were poor or 'rich' in one period were unlikely to be so in the longer term. Disadvantaged groups such as lone mothers, individuals affected by unemployment or people living together with more than two children also had higher staying probabilities in lower income classes and lower exit rates from poverty. Despite considerable heterogeneity in staying probabilities, an index measuring overall mobility did not differ much across different subpopulations because low staying probabilities at one end of the distribution were usually compensated by high staying probabilities at the other end.

Overall mobility in West Germany was slightly lower in 1998 than in 1990. Results for different subgroups in different years were generally very similar, suggesting a high degree of stationarity. A long-term comparison for West Germany suggests that the eighties' covariance structure did not differ markedly from that of the nineties. The main difference between the two decades was a larger variance and a higher persistence of transitory shocks in the eighties.

This rather stationary picture of the west German distribution was contrasted by a dynamic development in East Germany during the same period. As a consequence of reunification and the transition from a state-planned to a market economy, East Germany experienced a sharp increase in income inequality in 1990. Subsequently, inequality did not change until 1996, when it slightly fell. Between 35 and 52 percent of east German income inequality were accounted for by differences in observed individual characteristics.

In East Germany, the decomposition of income into permanent and transitory parts was much more characterized by non-stationarity than in West Germany. The importance of the permanent income component increased throughout the nineties. This was probably the result of the enormous wage growth, which increased income differences induced by persistent unobserved differences bet- 
ween individuals. As a consequence, the share of the permanent component in overall variance - and therefore the persistence of income inequality - rose from values between 10 and 20 percent in 1990 to values between 50 to 70 percent in 1998 .

In comparison with West Germany, east German incomes were more compressed around the center of the distribution, especially in 1990. East Germans generally experienced low poverty rates and small chances of being 'rich'. This was also true of the distribution of permanent incomes at the beginning of the nineties, implying that for the vast majority of East Germans, poverty or very high incomes were a rather transitory phenomenon during that time. In 1990, the average duration of an individual in poverty was 1.45 years. By 1998, poverty had become more persistent and the average duration of a poverty spell was 1.67 years.

The composition of disadvantaged groups was similar to the one in West Germany, although the severity of cases underwent some changes. In 1990, the most disadvantaged groups were lone mothers with more than two children, low-skilled or single pensioners, and - to a certain extent - individuals affected by unemployment. By 1998, unemployment had become the main poverty risk as in West Germany, whereas pensioners had improved their relative position dramatically and the adverse effect of children had diminished. East German income mobility was particularly high during the first years of the transition process, but converged to the lower west German level towards the end of the nineties.

Both the results for East and the ones for West Germany show that a considerable share of poverty and inequality in Germany is indeed permanent. This means that policies aiming at reducing poverty or inequality will have a limited effect unless they tackle the permanent differences between individuals, i.e. differences in education, employment status and living arrangements. The analysis has also shown that, in order to be effective, anti-poverty policies should especially target lone mother households, individuals affected by unemployment and households with many children.

Finally, this paper also addressed the problem of clustered observations at the household level and its effects on standard errors and test statistics. The results indicate that standard errors based on the independence assumption are generally too low, leading to potentially wrong statistical inferences. In the data sets analyzed here, standard errors based on the independence assumption were between 11 and 37 percent lower (23 percent on average) than those based on clustering. ${ }^{18}$ The difference was even more pronounced for Wald statistics, reversing the result of a test in one case (see section 4.1).

\footnotetext{
${ }^{18}$ Between 11 and 28 percent (20 percent on average) in the west German sample (compare Table A1) and between 15 and 37 percent (26 percent on average) in the case of the east German sample (see Table A2).
} 


\section{Appendix}

— Table A1 about here -

— Table A2 about here - 


\section{$7 \quad$ References}

Abowd, J.M. and D. Card (1989): On the Covariance Structure of Earnings and Hours Changes, Econometrica 57, $411-445$.

Atkinson, A.B., F. Bourguignon and C. Morrison (1992): Empirical Studies of Earnings Mobility, Harwood Academic Publishers, Chur.

Baker, M. (1997): Growth-Rate Heterogeneity and the Covariance Structure of Life-Cycle Earnings, Journal of Labor Economics 15, 338 - 375.

Biewen, M. (2001): Measuring the Effects of Socio-Economic Variables on the Income Distribution: An Application to the East German Transition Process, Review of Economics and Statistics 83, 185-190.

Binder, D.A. (1983): On the Variances of Asymptotically Normal Estimators from Complex Sample Surveys, International Statistical Review 51, 293 - 300.

Burda, M. and C.M. Schmidt (1997): Getting behind the East-West Wage Differential: Theory and Evidence, in: R. Pohl (ed.): Wandeln oder Weichen - Herausforderungen der wirtschaftlichen Integration für Deutschland, Wirtschaft im Wandel 3/97, Sonderheft.

Burkhauser, R.V., D. Holtz-Eakin and S.E. Rhody (1997): Labor Earnings Mobility and Inequality in the United States and Germany during the Growth Years of the 1980s, International Economic Review 38, pp. 775 - 794.

Cappellari, L. (2000): The Dynamics and Inequality of Italian Male Earnings: permanent changes or transitory fluctuations?, Working Paper 2000-41, University of Essex.

Chamberlain, G. (1984): Panel Data, in: Griliches, Z. and M.D. Intriligator (eds.): Handbook of Econometrics, Vol. 2, ch. 22.

Cochran, W.G. (1977): Sampling Techniques, 3d ed., Wiley, New York.

Dickens, R. (2000): The Evolution of Individual Male Earnings in Great Britain: 1979-95, The Economic Journal 110, 27 - 49.

Devicienti, F. (2001): Estimating Poverty Persistence in Britain, Working Paper, LABORatorio Riccardo Revelli, Centre for Employment Studies, Turin.

Duncan, G.J. (1983): The Implications of Changing Family Composition for the Dynamic Analysis of Family Economic Well-Being, in: Cowell, F. and A.B. Atkinson, Panel Data on Incomes, London 
School of Economics, $203-239$.

Fourarge, D. and R. Muffels (2000): Persistent Poverty in the Netherlands, Germany and the UK: A Model-based Approach Using Panel Data from the 1990s, EPAG Working Paper 15, University of Essex.

Haisken-DeNew, J.P. and J. Frick (eds.) (2000): Desk Top Companion to the German Socio-Economic Panel Study (GSOEP) - Version 4.0, Deutsches Institut für Wirtschaftsforschung (DIW), Berlin.

Hauser, R. and G. Wagner (1996): Die Einkommensverteilung in Ostdeutschland - Darstellung, Vergleich und Determinanten für die Jahre 1990 bis 1994, in: Kleinhenz, G. and R. Hauser (1996)(eds.): Sozialpolitik im vereinten Deutschland, Schriften des Vereins für Socialpolitik, Bd. 208, 79 - 128.

Korn, E.L. and B.I. Graubard (1990): Simultaneous Testing of Regression Coefficients With Complex Survey Data: Use of Bonferroni t-Statistics, The American Statistician 44, 270 - 276.

Lillard, L.A. and Y. Weiss (1979): Components of Variation in Panel Earnings Data: American Scientists $1960-70$, Econometrica 47, 437 - 455.

Lillard, L.A. and R.J. Willis (1978): Dynamic Aspects of Earnings Mobility, Econometrica 46, 985 1012.

MaCurdy, Th.E. (1982): The Use of Time Series Processes to Model the Error Structure of Earnings in a Longitudinal Data Analysis, Journal of Econometrics 18, 83 - 114.

Moffitt, R.A. and P. Gottschalk (1995): Trends in the Autocovariance Structure of Earnings in the U.S.: 1969 - 87, Working Paper, Johns Hopkins University.

Ramos, X. (2001): The dynamics of individual male earnings in Britain: 1991 - 1998, Working Paper 2001-15, University of Essex.

Schluter, C. (1998): Statistical inference with mobility indices, Economics Letters 59, 157-162.

Skinner, C.J., D. Holt and T.M.F. Smith (1989): Analysis of Complex Surveys, Chichester, Wiley.

SOEP Group (2001): The German Socio-Economic Panel (GSOEP) after more than 15 years, in: Holst, E., D.R. Lillard and T.A. DiPrete (eds.): Proceedings of the 2000 Fourth International Conference of German Socio-Economic Panel Study Users (GSOEP2000), Vierteljahreshefte zur Wirtschaftsforschung 70, pp. 7 - 14 .

Stevens, A.H. (1999): Climbing Out of Poverty, Falling Back In, Measuring the Persistence of Poverty Over Multiple Spells, Journal of Human Resources 34, 557 - 588. 
Wagner, G., R.V. Burkhauser and Behringer, F. (1993): The English Language Public Use File of the German Socio-Economic Panel Study, Journal of Human Resources 28, pp. 429 - 433. 


\section{Figures}

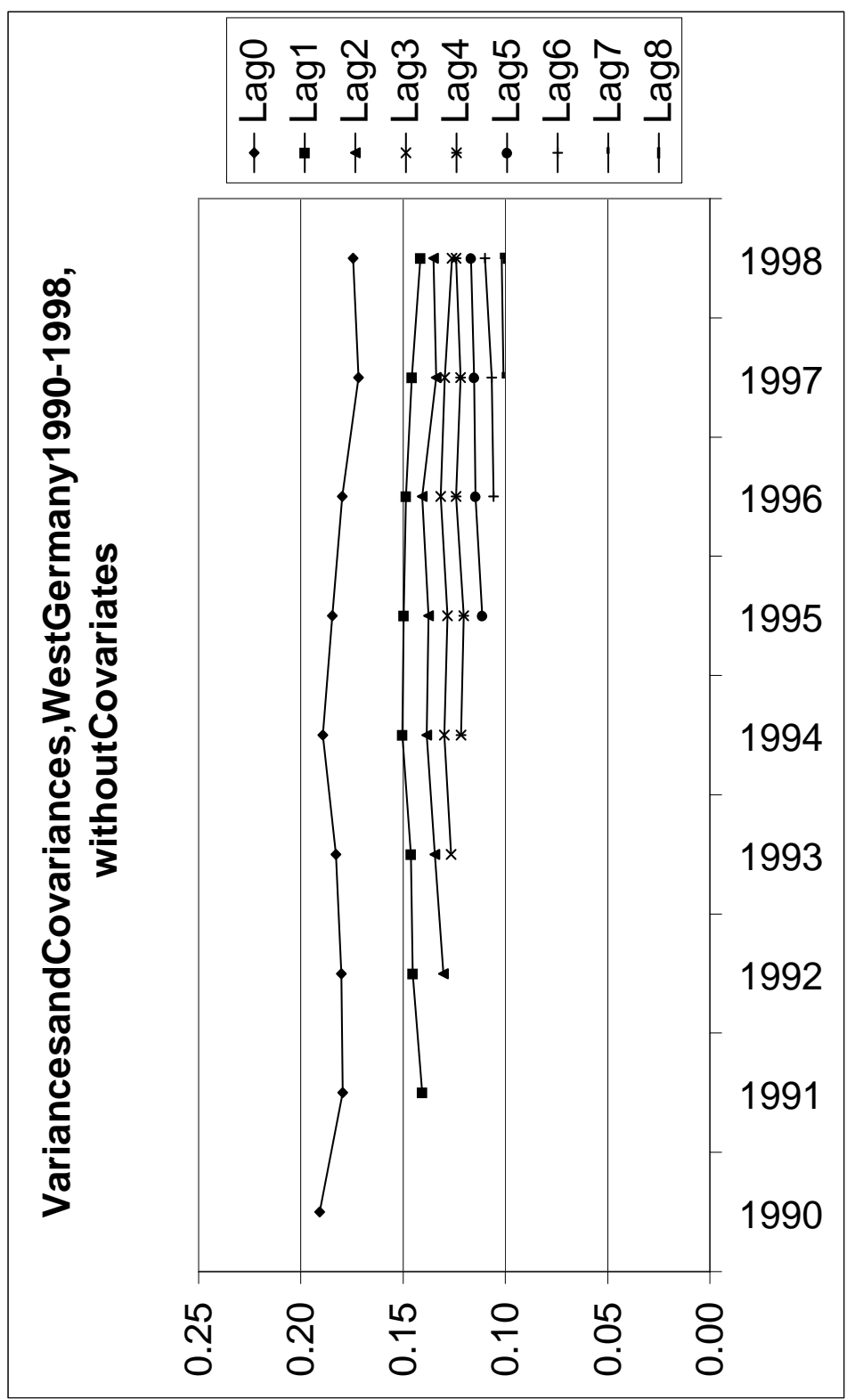

Figure 1: Empirical variances and covariances of equivalent income,

West Germany 1990 - 1998, without covariates. 


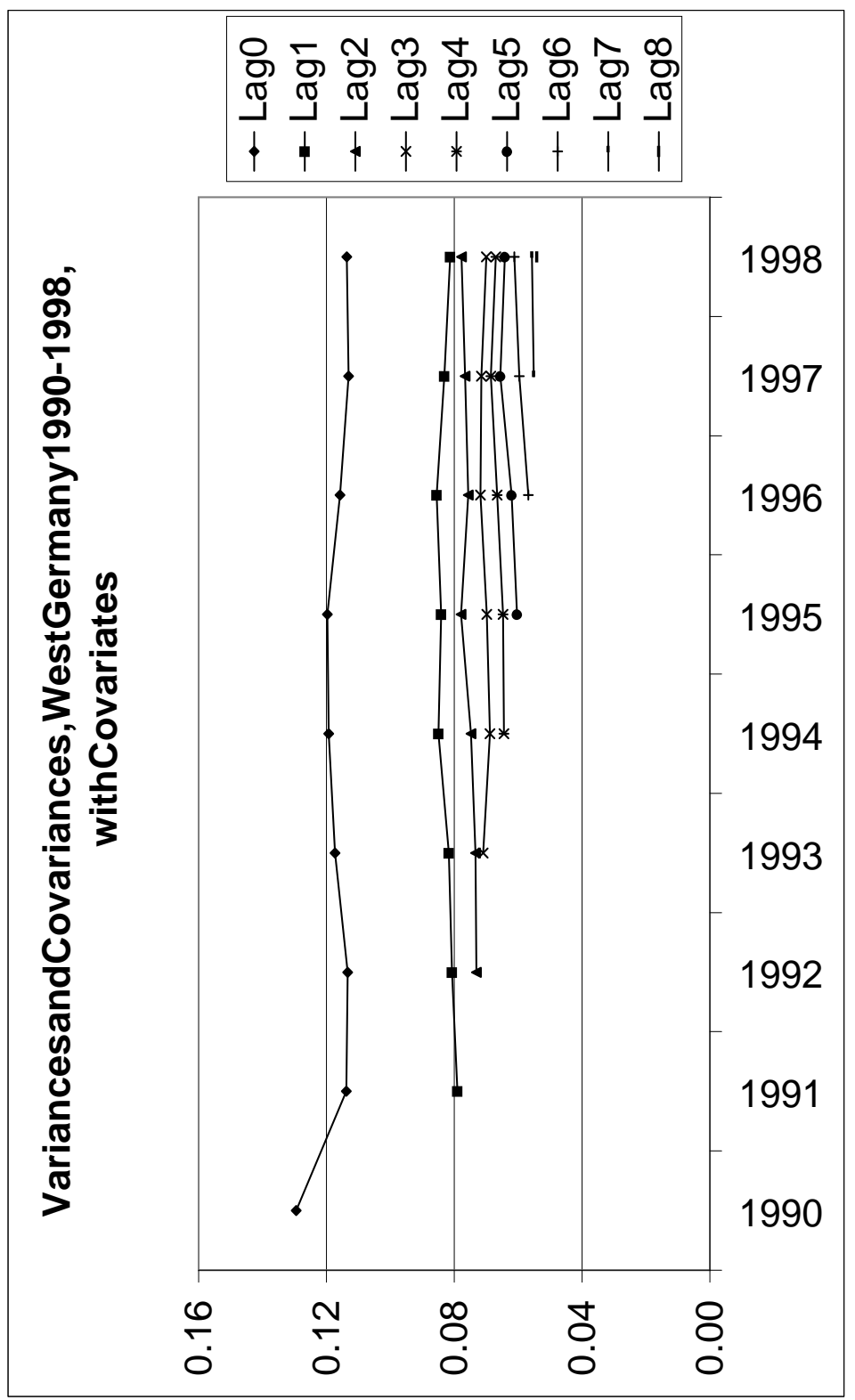

Figure 2: Empirical variances and covariances of equivalent income, West Germany 1990 - 1998, with covariates. 


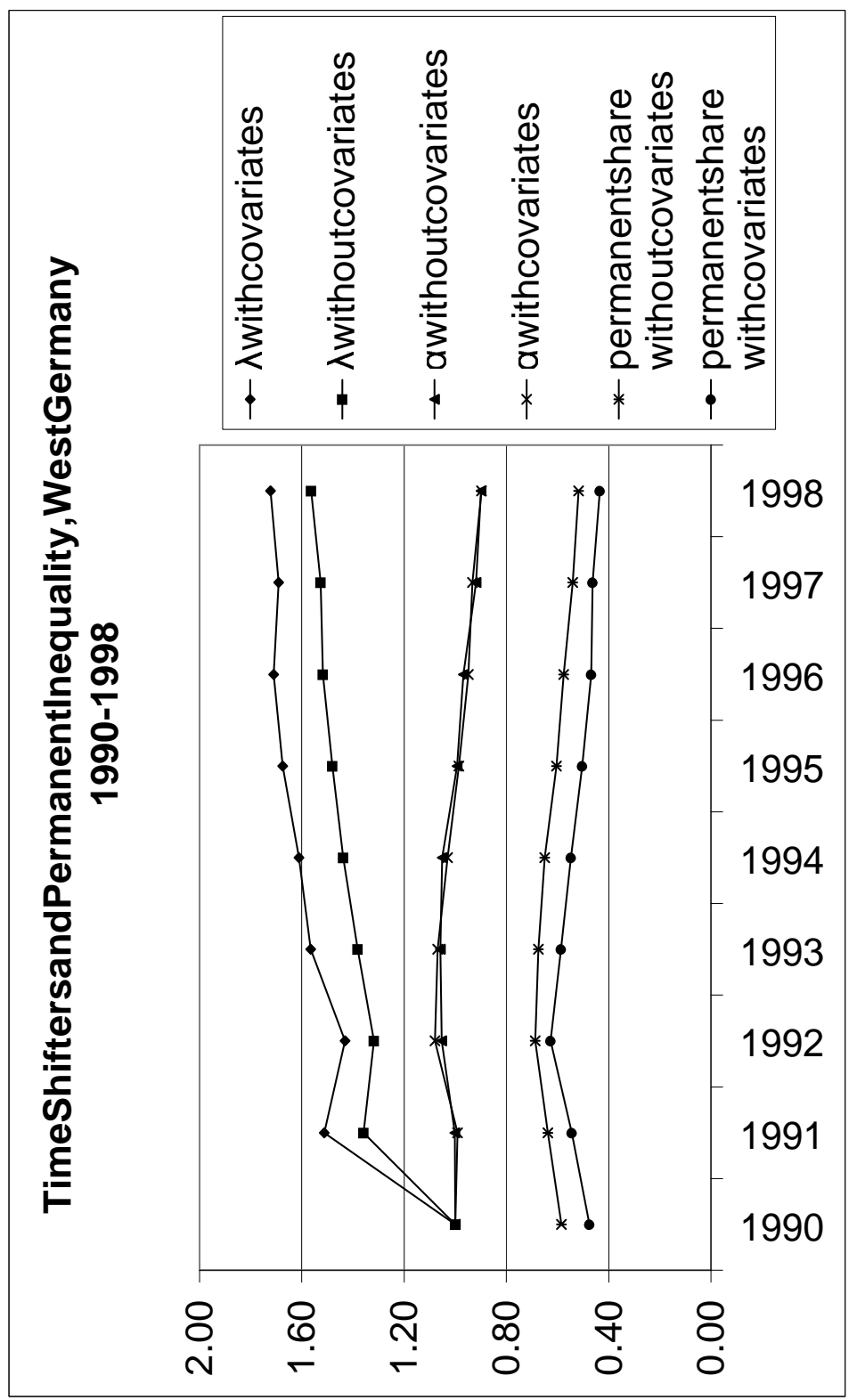

Figure 3: Time shifters and permanent inequality, West Germany 1990 - 1998. 


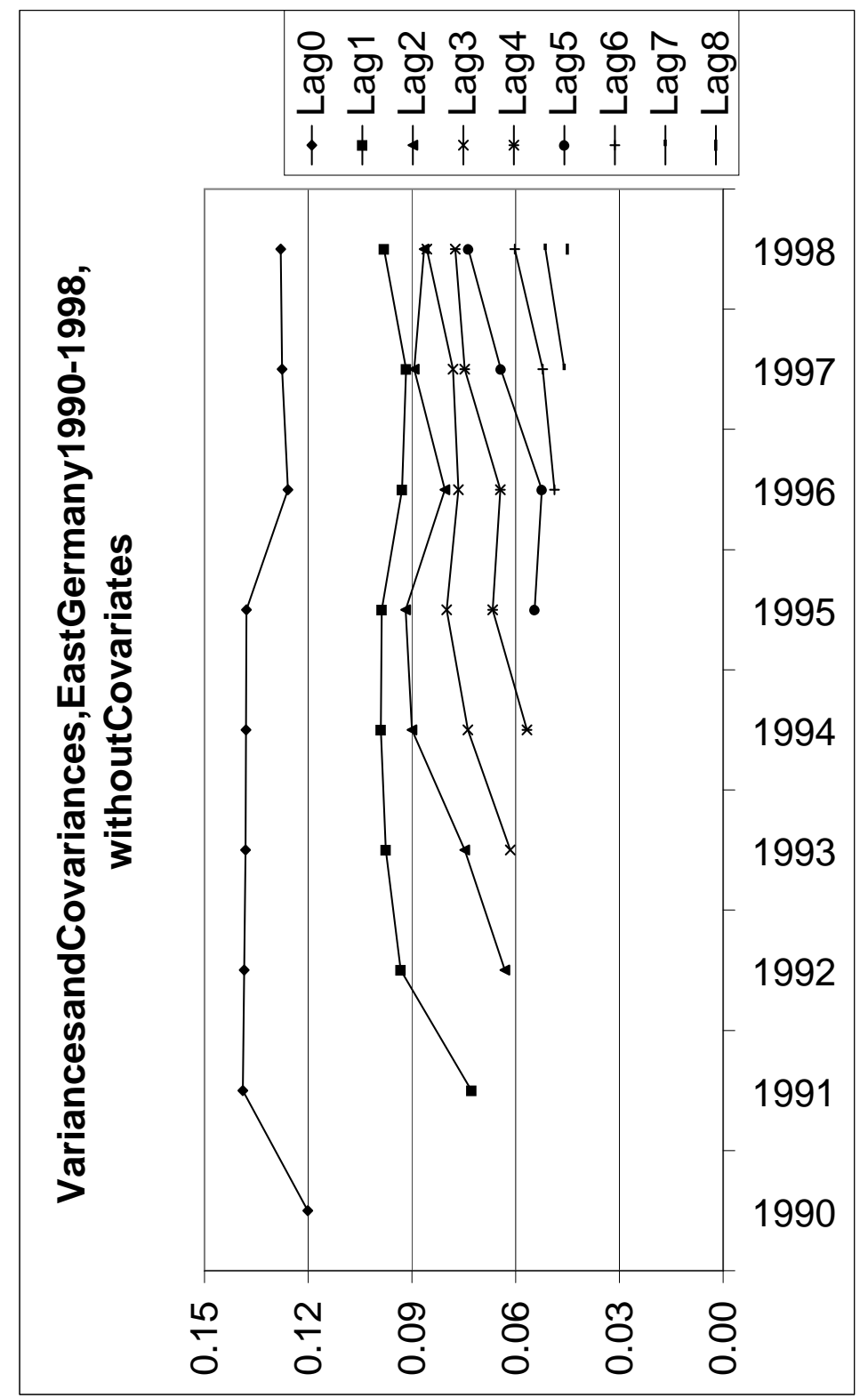

Figure 4: Empirical variances and covariances of equivalent income, East Germany 1990 - 1998, without covariates. 


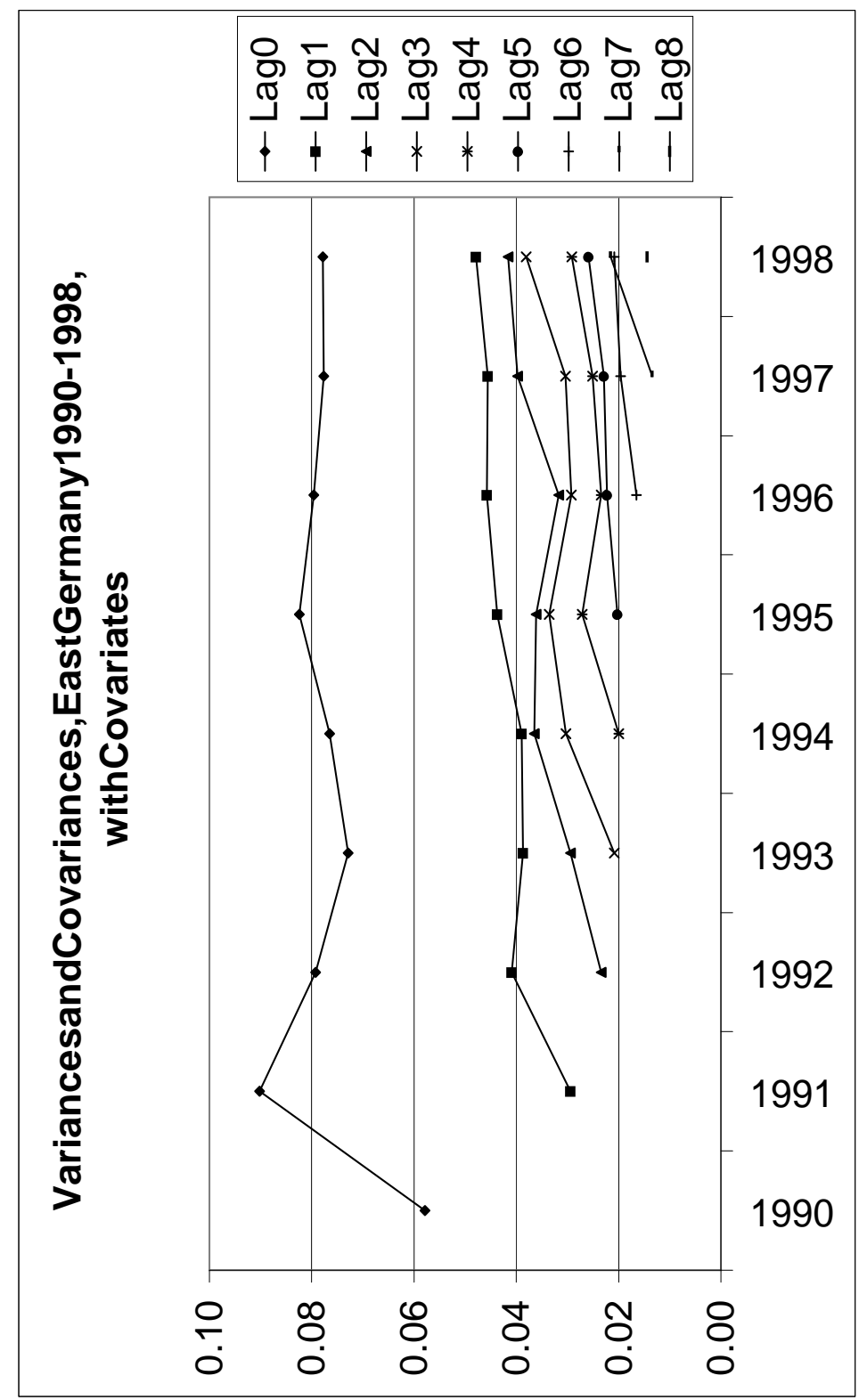

Figure 5: Empirical variances and covariances of equivalent income, East Germany 1990 - 1998, with covariates. 


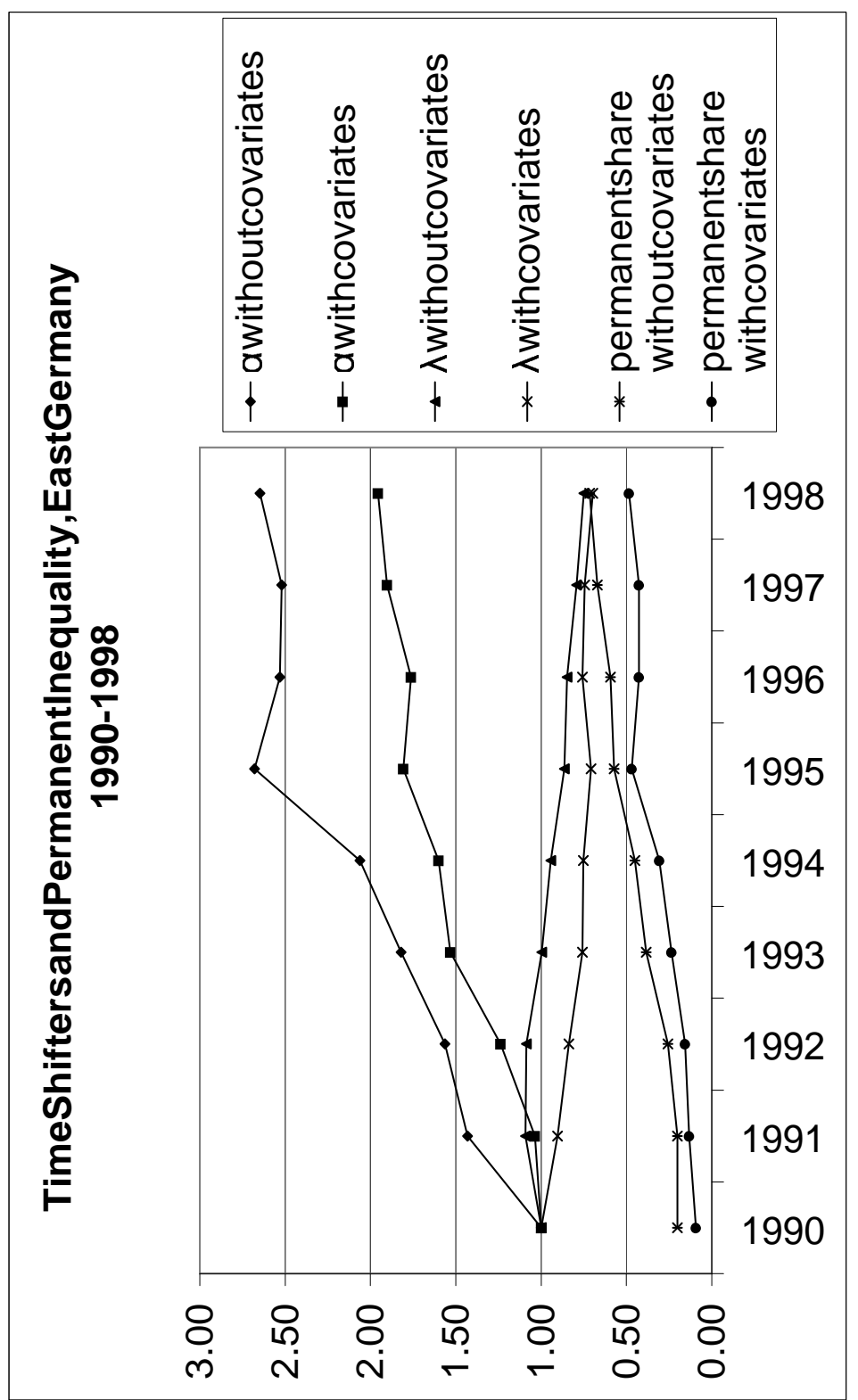

Figure 6: Time shifters and permanent inequality, East Germany 1990 - 1998. 


\section{Tables}

Table 1. Selected first stage regressions of log equivalent income on household characteristics, West and East Germany (standard errors in parentheses ${ }^{a}$ )

\begin{tabular}{|c|c|c|c|c|c|c|}
\hline \multicolumn{2}{|l|}{ Variables } & \multirow[t]{2}{*}{ West ' $90^{b}$} & $\begin{array}{r}\text { West } ' 98^{b} \\
0.1842\end{array}$ & East $' 90^{b}$ & $\begin{array}{r}\text { East } ' 98^{b} \\
-0.1534\end{array}$ & \multirow[t]{2}{*}{ West ' $84^{\prime}$} \\
\hline & living in East & & $\begin{array}{r}0.1842 \\
(0.1815)\end{array}$ & & $\begin{array}{r}-0.1534 \\
(0.0553)\end{array}$ & \\
\hline & female household head & -0.0522 & -0.0615 & -0.0176 & -0.0139 & -0.1394 \\
\hline & & $(0.0278)$ & $(0.0242)$ & $(0.0159)$ & $(0.0174)$ & $(0.0475)$ \\
\hline & non-German & -0.0897 & -0.0887 & 0.1666 & -0.2295 & -0.0410 \\
\hline & & $(0.0439)$ & $(0.0310)$ & $(0.0803)$ & $(0.0574)$ & $(0.0285)$ \\
\hline \multirow[t]{6}{*}{ \# of children } & $0-6$ years & -0.1131 & -0.0247 & -0.1174 & -0.0553 & -0.1317 \\
\hline & & $(0.0178)$ & $(0.0277)$ & $(0.0176)$ & $(0.0295)$ & $(0.0145)$ \\
\hline & $7-11$ years & -0.0952 & -0.0202 & -0.0603 & -0.0819 & -0.1115 \\
\hline & & $(0.0161)$ & $(0.0147)$ & $(0.0149)$ & $(0.0205)$ & $(0.0155)$ \\
\hline & $12-17$ years & -0.0894 & -0.0798 & -0.0596 & -0.0536 & -0.0838 \\
\hline & & $(0.0222)$ & $(0.0156)$ & $(0.0145)$ & $(0.0164)$ & $(0.0145)$ \\
\hline \multirow{10}{*}{$\begin{array}{l}\text { \# of household members } \\
18-41 \text { years }\end{array}$} & employed, high-skilled & 0.4666 & 0.3394 & 0.4244 & 0.3334 & 0.4871 \\
\hline & & $(0.0303)$ & $(0.0268)$ & $(0.0276)$ & $(0.0405)$ & $(0.0294)$ \\
\hline & employed, medium-skilled & 0.1936 & 0.1929 & 0.2842 & 0.2068 & 0.2328 \\
\hline & & $(0.0212)$ & $(0.0191)$ & $(0.0194)$ & $(0.0213)$ & $(0.0193)$ \\
\hline & employed, low-skilled & 0.1243 & 0.1074 & 0.2841 & 0.1379 & 0.1414 \\
\hline & & $(0.0307)$ & $(0.0259)$ & $(0.0711)$ & $(0.0470)$ & $(0.0227)$ \\
\hline & unemployed & -0.1416 & -0.1650 & 0.2274 & -0.1048 & -0.0890 \\
\hline & & $(0.0491)$ & $(0.0544)$ & $(0.0417)$ & $(0.0278)$ & $(0.0773)$ \\
\hline & non-employed/other & -0.0333 & -0.0912 & -0.0173 & 0.0016 & -0.0785 \\
\hline & & $(0.0194)$ & $(0.0190)$ & $(0.0235)$ & $(0.0170)$ & $(0.0142)$ \\
\hline \multirow{16}{*}{$\begin{array}{l}\text { \# of household members } \\
42-64 \text { years }\end{array}$} & employed, high-skilled & 0.5713 & 0.5101 & 0.5222 & 0.4308 & 0.6140 \\
\hline & & $(0.0425)$ & $(0.0437)$ & $(0.0307)$ & $(0.0310)$ & $(0.0372)$ \\
\hline & employed, medium-skilled & 0.2271 & 0.2446 & 0.2963 & 0.2288 & 0.2303 \\
\hline & & $(0.0228)$ & $(0.0227)$ & $(0.0193)$ & $(0.0200)$ & $(0.0202)$ \\
\hline & employed, low-skilled & 0.0598 & 0.0912 & 0.1372 & 0.1741 & 0.0929 \\
\hline & & $(0.0442)$ & $(0.0409)$ & $(0.0377)$ & $(0.0688)$ & $(0.0265)$ \\
\hline & unemployed & -0.0281 & -0.1001 & & 0.0086 & -0.1603 \\
\hline & & $(0.1052)$ & $(0.0397)$ & & $(0.0307)$ & $(0.0633)$ \\
\hline & retired, high-skilled & 0.2945 & 0.3609 & 0.4865 & 0.3887 & 0.5861 \\
\hline & & $(0.0737)$ & $(0.0966)$ & $(0.1001)$ & $(0.0675)$ & $(0.0963)$ \\
\hline & retired, medium-skilled & 0.0332 & 0.0573 & 0.1190 & 0.1356 & 0.0324 \\
\hline & & $(0.0401)$ & $(0.0412)$ & $(0.0333)$ & $(0.0245)$ & $(0.0281)$ \\
\hline & retired, low-skilled & 0.0239 & 0.0092 & 0.0584 & -0.0615 & -0.0210 \\
\hline & & $(0.0549)$ & $(0.0300)$ & $(0.0739)$ & $(0.0682)$ & $(0.0441)$ \\
\hline & non-employed/other & -0.0008 & 0.0467 & -0.0842 & 0.0554 & -0.0319 \\
\hline & & $(0.0273)$ & $(0.0251)$ & $(0.0689)$ & $(0.0595)$ & $(0.0333)$ \\
\hline \multirow{12}{*}{$\begin{array}{l}\text { \# of household members } \\
\text { over } 64 \text { years }\end{array}$} & employed & -0.0594 & 0.1872 & 0.4063 & 0.1577 & 0.4144 \\
\hline & & $(0.1740)$ & $(0.0805)$ & $(0.1002)$ & $(0.1422)$ & $(0.1825)$ \\
\hline & retired, high-skilled & 0.3770 & 0.4216 & 0.2196 & 0.2446 & 0.4089 \\
\hline & & $(0.1011)$ & $(0.0493)$ & $(0.0427)$ & $(0.0687)$ & $(0.1798)$ \\
\hline & retired, medium-skilled & 0.0760 & 0.1096 & 0.0709 & 0.1754 & 0.1306 \\
\hline & & $(0.0303)$ & $(0.0239)$ & $(0.0284)$ & $(0.0231)$ & $(0.0284)$ \\
\hline & retired, low-skilled & -0.0946 & -0.0509 & -0.0527 & 0.1250 & -0.1134 \\
\hline & & $(0.0420)$ & $(0.0270)$ & $(0.0421)$ & $(0.0329)$ & $(0.0371)$ \\
\hline & non-employed/other & -0.0858 & 0.0033 & -0.2523 & 0.1944 & -.2064 \\
\hline & & $(0.0854)$ & $(0.0599)$ & $(0.1190)$ & $(0.0732)$ & $(0.0672)$ \\
\hline & constant & 7.4377 & 7.6405 & 6.4566 & 7.5208 & 7.1903 \\
\hline & & $(0.0402)$ & $(0.0351)$ & $(0.0411)$ & $(0.0656)$ & $(0.0357)$ \\
\hline
\end{tabular}


Table 2. Empirical variance covariance matrix of log equivalent income, West Germany, 1990 - 98, no covariates

(standard errors in parentheses ${ }^{a}$ )

\begin{tabular}{|c|c|c|c|c|c|c|c|c|c|}
\hline Year & 1990 & 1991 & 1992 & 1993 & 1994 & 1995 & 1996 & 1997 & 1998 \\
\hline 1990 & $\begin{array}{r}0.1907 \\
(0.0109)\end{array}$ & & & & & & & & \\
\hline 1991 & $\begin{array}{r}0.1407 \\
(0.0076)\end{array}$ & $\begin{array}{r}0.1795 \\
(0.0081)\end{array}$ & & & & & & & \\
\hline 1992 & $\begin{array}{r}0.1302 \\
(0.0080)\end{array}$ & $\begin{array}{r}0.1452 \\
(0.0078)\end{array}$ & $\begin{array}{r}0.1802 \\
(0.0090)\end{array}$ & & & & & & \\
\hline 1993 & $\begin{array}{r}0.1266 \\
(0.0084)\end{array}$ & $\begin{array}{r}0.1344 \\
(0.0074)\end{array}$ & $\begin{array}{r}0.1462 \\
(0.0081)\end{array}$ & $\begin{array}{r}0.1829 \\
(0.0090)\end{array}$ & & & & & \\
\hline 1994 & $\begin{array}{r}0.1216 \\
(0.0083)\end{array}$ & $\begin{array}{r}0.1300 \\
(0.0072)\end{array}$ & $\begin{array}{r}0.1385 \\
(0.0077)\end{array}$ & $\begin{array}{r}0.1504 \\
(0.0082)\end{array}$ & $\begin{array}{r}0.1894 \\
(0.0092)\end{array}$ & & & & \\
\hline 1995 & $\begin{array}{r}0.1113 \\
(0.0074)\end{array}$ & $\begin{array}{r}0.1203 \\
(0.0066)\end{array}$ & $\begin{array}{r}0.1282 \\
(0.0070)\end{array}$ & $\begin{array}{r}0.1375 \\
(0.0071)\end{array}$ & $\begin{array}{r}0.1498 \\
(0.0074)\end{array}$ & $\begin{array}{r}0.1847 \\
(0.0086)\end{array}$ & & & \\
\hline 1996 & $\begin{array}{r}0.1057 \\
(0.0074)\end{array}$ & $\begin{array}{r}0.1147 \\
(0.0067)\end{array}$ & $\begin{array}{r}0.1242 \\
(0.0070)\end{array}$ & $\begin{array}{r}0.1315 \\
(0.0072)\end{array}$ & $\begin{array}{r}0.1407 \\
(0.0075)\end{array}$ & $\begin{array}{r}0.1487 \\
(0.0073)\end{array}$ & $\begin{array}{r}0.1799 \\
(0.0076)\end{array}$ & & \\
\hline 1997 & $\begin{array}{r}0.1009 \\
(0.0072)\end{array}$ & $\begin{array}{r}0.1068 \\
(0.0061)\end{array}$ & $\begin{array}{r}0.1153 \\
(0.0065)\end{array}$ & $\begin{array}{r}0.1220 \\
(0.0068)\end{array}$ & $\begin{array}{r}0.1296 \\
(0.0072)\end{array}$ & $\begin{array}{r}0.1339 \\
(0.0065)\end{array}$ & $\begin{array}{r}0.1457 \\
(0.0067)\end{array}$ & $\begin{array}{r}0.1718 \\
(0.0068)\end{array}$ & \\
\hline 1998 & $\begin{array}{r}0.1006 \\
(0.0071)\end{array}$ & $\begin{array}{r}0.1018 \\
(0.0063)\end{array}$ & $\begin{array}{r}0.1100 \\
(0.0066)\end{array}$ & $\begin{array}{r}0.1167 \\
(0.0067)\end{array}$ & $\begin{array}{r}0.1241 \\
(0.0072)\end{array}$ & $\begin{array}{r}0.1260 \\
(0.0064)\end{array}$ & $\begin{array}{r}0.1352 \\
(0.0065)\end{array}$ & $\begin{array}{r}0.1417 \\
(0.0064)\end{array}$ & $\begin{array}{r}0.1744 \\
(0.0067)\end{array}$ \\
\hline
\end{tabular}

${ }^{a}$ Standard errors account for household clustering

Table 3. Empirical variance covariance matrix of log equivalent income, West Germany, 1990 - 98, with covariates (standard errors in parentheses ${ }^{a}$ )

\begin{tabular}{|c|c|c|c|c|c|c|c|c|c|}
\hline Year & 1990 & 1991 & 1992 & 1993 & 1994 & 1995 & 1996 & 1997 & 1998 \\
\hline 1990 & $\begin{array}{r}0.1295 \\
(0.0095)\end{array}$ & & & & & & & & \\
\hline 1991 & $\begin{array}{r}0.0791 \\
(0.0051)\end{array}$ & $\begin{array}{r}0.1137 \\
(0.0053)\end{array}$ & & & & & & & \\
\hline 1992 & $\begin{array}{r}0.0731 \\
(0.0054)\end{array}$ & $\begin{array}{r}0.0807 \\
(0.0046)\end{array}$ & $\begin{array}{r}0.1134 \\
(0.0055)\end{array}$ & & & & & & \\
\hline 1993 & $\begin{array}{r}0.0709 \\
(0.0062)\end{array}$ & $\begin{array}{r}0.0734 \\
(0.0046)\end{array}$ & $\begin{array}{r}0.0816 \\
(0.0051)\end{array}$ & $\begin{array}{r}0.1174 \\
(0.0064)\end{array}$ & & & & & \\
\hline 1994 & $\begin{array}{r}0.0645 \\
(0.0057)\end{array}$ & $\begin{array}{r}0.0689 \\
(0.0047)\end{array}$ & $\begin{array}{r}0.0748 \\
(0.0051)\end{array}$ & $\begin{array}{r}0.0850 \\
(0.0056)\end{array}$ & $\begin{array}{r}0.1193 \\
(0.0068)\end{array}$ & & & & \\
\hline 1995 & $\begin{array}{r}0.0604 \\
(0.0050)\end{array}$ & $\begin{array}{r}0.0648 \\
(0.0040)\end{array}$ & $\begin{array}{r}0.0699 \\
(0.0044)\end{array}$ & $\begin{array}{r}0.0779 \\
(0.0045)\end{array}$ & $\begin{array}{r}0.0840 \\
(0.0050)\end{array}$ & $\begin{array}{r}0.1197 \\
(0.0069)\end{array}$ & & & \\
\hline 1996 & $\begin{array}{r}0.0568 \\
(0.0048)\end{array}$ & $\begin{array}{r}0.0621 \\
(0.0040)\end{array}$ & $\begin{array}{r}0.0666 \\
(0.0044)\end{array}$ & $\begin{array}{r}0.0718 \\
(0.0045)\end{array}$ & $\begin{array}{r}0.0756 \\
(0.0049)\end{array}$ & $\begin{array}{r}0.0855 \\
(0.0049)\end{array}$ & $\begin{array}{r}0.1158 \\
(0.0054)\end{array}$ & & \\
\hline 1997 & $\begin{array}{r}0.0551 \\
(0.0052)\end{array}$ & $\begin{array}{r}0.0597 \\
(0.0038)\end{array}$ & $\begin{array}{r}0.0655 \\
(0.0045)\end{array}$ & $\begin{array}{r}0.0686 \\
(0.0046)\end{array}$ & $\begin{array}{r}0.0715 \\
(0.0050)\end{array}$ & $\begin{array}{r}0.0766 \\
(0.0046)\end{array}$ & $\begin{array}{r}0.0831 \\
(0.0048)\end{array}$ & $\begin{array}{r}0.1131 \\
(0.0052)\end{array}$ & \\
\hline 1998 & $\begin{array}{r}0.0541 \\
(0.0050)\end{array}$ & $\begin{array}{r}0.0557 \\
(0.0038)\end{array}$ & $\begin{array}{r}0.0612 \\
(0.0044)\end{array}$ & $\begin{array}{r}0.0641 \\
(0.0044)\end{array}$ & $\begin{array}{r}0.0670 \\
(0.0048)\end{array}$ & $\begin{array}{r}0.0699 \\
(0.0043)\end{array}$ & $\begin{array}{r}0.0778 \\
(0.0045)\end{array}$ & $\begin{array}{r}0.0813 \\
(0.0047)\end{array}$ & $\begin{array}{r}0.1136 \\
(0.0049)\end{array}$ \\
\hline
\end{tabular}

${ }^{a}$ Standard errors account for household clustering 
Table 4. Parameter estimates, West Germany, 1990 - 98 (standard errors in parentheses ${ }^{a}$ )

\begin{tabular}{|c|c|c|c|c|c|c|}
\hline \multirow[t]{2}{*}{ Parameter } & \multicolumn{3}{|c|}{ without covariates } & \multicolumn{3}{|c|}{ with covariates } \\
\hline & (S1) & $(\mathrm{S} 2)$ & (S3) & (S1) & $(\mathrm{S} 2)$ & (S3) \\
\hline \multirow[t]{2}{*}{$\sigma_{\mu}^{2}$} & 0.1274 & 0.1000 & 0.1116 & 0.0705 & 0.0599 & 0.0613 \\
\hline & $(0.0064)$ & $(0.0196)$ & $(0.013)$ & $(0.004)$ & $(0.0057)$ & $(0.0101)$ \\
\hline \multirow[t]{2}{*}{$\sigma_{\nu_{1989}}^{2}$} & & 0.1145 & 0.4263 & & 0.1117 & 0.6729 \\
\hline & & $(0.0331)$ & $(0.320)$ & & $(0.0372)$ & $(0.9480)$ \\
\hline \multirow[t]{2}{*}{$\rho$} & & 0.7403 & 0.3581 & & 0.6265 & 0.2752 \\
\hline & & $(0.1309)$ & $(0.121)$ & & $(0.0863)$ & $(0.1779)$ \\
\hline \multirow[t]{2}{*}{$\theta$} & & -0.2967 & -0.279 & & -0.3041 & -0.3702 \\
\hline & & $(0.0846)$ & $(0.036)$ & & $(0.0669)$ & $(0.0517)$ \\
\hline \multirow[t]{2}{*}{$\alpha_{1991}{ }^{b}$} & & & 1.0018 & & & 0.9913 \\
\hline & & & $(0.042)$ & & & $(0.0705)$ \\
\hline \multirow[t]{2}{*}{$\alpha_{1992}$} & & & 1.0536 & & & 1.0788 \\
\hline & & & $(0.076)$ & & & $(0.0728)$ \\
\hline \multirow[t]{2}{*}{$\alpha_{1993}$} & & & 1.0579 & & & 1.0696 \\
\hline & & & $(0.091)$ & & & $(0.0926)$ \\
\hline \multirow[t]{2}{*}{$\alpha_{1994}$} & & & 1.0514 & & & 1.0307 \\
\hline & & & $(0.093)$ & & & $(0.1040)$ \\
\hline \multirow[t]{2}{*}{$\alpha_{1995}$} & & & 0.9924 & & & 0.9861 \\
\hline & & & $(0.086)$ & & & $(0.1030)$ \\
\hline \multirow[t]{2}{*}{$\alpha_{1996}$} & & & 0.9688 & & & 0.9479 \\
\hline & & & $(0.086)$ & & & $(0.1036)$ \\
\hline \multirow[t]{2}{*}{$\alpha_{1997}$} & & & 0.9194 & & & 0.9326 \\
\hline & & & $(0.080)$ & & & $(0.1006)$ \\
\hline \multirow[t]{2}{*}{$\alpha_{1998}$} & & & 0.9000 & & & 0.8981 \\
\hline & & & $(0.080)$ & & & $(0.1050)$ \\
\hline \multirow[t]{2}{*}{$\lambda_{1991}^{b}$} & & & 1.3582 & & & 1.5132 \\
\hline & & & $(0.202)$ & & & $(0.4393)$ \\
\hline \multirow[t]{2}{*}{$\lambda_{1992}$} & & & 1.3187 & & & 1.4312 \\
\hline & & & $(0.240)$ & & & $(0.4688)$ \\
\hline \multirow[t]{2}{*}{$\lambda_{1993}$} & & & 1.3813 & & & 1.5661 \\
\hline & & & $(0.269)$ & & & $(0.5455)$ \\
\hline$\lambda_{1994}$ & & & 1.4385 & & & 1.6119 \\
\hline & & & $(0.267)$ & & & $(0.5652)$ \\
\hline$\lambda_{1995}$ & & & 1.4802 & & & 1.6750 \\
\hline & & & $(0.268)$ & & & $(0.5778)$ \\
\hline$\lambda_{1996}$ & & & 1.5171 & & & 1.7109 \\
\hline & & & $(0.284)$ & & & $(0.6099)$ \\
\hline$\lambda_{1997}$ & & & 1.5263 & & & 1.6908 \\
\hline & & & $(0.289)$ & & & $(0.6167)$ \\
\hline$\lambda_{1998}$ & & & 1.5630 & & & 1.7233 \\
\hline & & & $(0.322)$ & & & $(0.6519)$ \\
\hline$\sigma_{\varepsilon}^{2}$ & 0.0541 & 0.0526 & 0.0277 & 0.0468 & 0.0457 & 0.0181 \\
\hline & $(0.0019)$ & $(0.0037)$ & $(0.008)$ & $(0.0016)$ & $(0.0021)$ & $(0.0122)$ \\
\hline$s_{1990^{c}}$ & 0.7020 & 0.5078 & 0.5854 & 0.6013 & 0.4397 & 0.4745 \\
\hline$s_{1991}$ & 0.7020 & 0.5340 & 0.6377 & 0.6013 & 0.4895 & 0.5441 \\
\hline$s_{1992}$ & 0.7020 & 0.5495 & 0.6865 & 0.6013 & 0.5123 & 0.6270 \\
\hline$s_{1993}$ & 0.7020 & 0.5584 & 0.6743 & 0.6013 & 0.5219 & 0.5871 \\
\hline$s_{1994}$ & 0.7020 & 0.5635 & 0.6500 & 0.6013 & 0.5257 & 0.5485 \\
\hline$s_{1995}$ & 0.7020 & 0.5662 & 0.6041 & 0.6013 & 0.5272 & 0.5034 \\
\hline$s_{1996}$ & 0.7020 & 0.5678 & 0.5753 & 0.6013 & 0.5278 & 0.4684 \\
\hline$s_{1997}$ & 0.7020 & 0.5686 & 0.5415 & 0.6013 & 0.5281 & 0.4630 \\
\hline$s_{1998}$ & 0.7020 & 0.5691 & 0.5168 & 0.6013 & 0.5281 & 0.4355 \\
\hline$S S R^{d}$ & 0.0079 & 0.0017 & 0.0001 & 0.0031 & 0.0010 & 0.0001 \\
\hline $\mathrm{p}$-value ${ }^{e}$ & & 0.0000 & 0.0002 & & 0.0000 & 0.0689 \\
\hline
\end{tabular}

(S1) $u_{i t}=\mu_{i}+\varepsilon_{i t}$ with $\operatorname{var}\left(\mu_{i}\right)=\sigma_{\mu}^{2}$ and $\operatorname{var}\left(\varepsilon_{i t}\right)=\sigma_{\varepsilon}^{2}$

(S2) $u_{i t}=\mu_{i}+\left[\rho v_{i t-1}+\theta \varepsilon_{i t-1}+\varepsilon_{i t}\right]$

(S3) $u_{i t}=\alpha_{t} \mu_{i}+\lambda_{t}\left[\rho v_{i t-1}+\theta \varepsilon_{i t-1}+\varepsilon_{i t}\right]$

In the case with no covariates just a constant was fitted, i.e. $x_{i t} \equiv 1$

a Standard errors account for household clustering (2503 clusters), see text for details

${ }^{b} \alpha_{1990}$ and $\lambda_{1990}$ were set to one for identification

${ }^{c}$ Share of permanent component in period variance $s_{t}=\alpha_{t}^{2} \sigma_{\mu}^{2} / \operatorname{var}\left(u_{t}\right)$

${ }^{d}$ Sum of squared residuals $S S R=(\operatorname{vech}(\Omega(\hat{\omega}))-\operatorname{vech}(M))^{\prime}(\operatorname{vech}(\Omega(\hat{\omega}))-\operatorname{vech}(M))$

$e$ Of an adjusted Wald-Test (see Korn/Graubard(1990)) of $H_{0}:(S(J-1))$ vs. $H_{1}:(S J), J=2,3$ 
Table 5. Population shares of income classes, West Germany, sample $1990-98$

\begin{tabular}{|c|c|c|c|c|c|c|c|c|c|c|c|c|}
\hline Subgroup & $P_{t}^{1}$ & $P_{t}^{2}$ & $P_{t}^{3}$ & $P_{t}^{4}$ & $P_{t}^{1, p}$ & $P_{t}^{2, p}$ & $P_{t}^{3, p}$ & $P_{t}^{4, p}$ & $r_{t}^{1}$ & $r_{t}^{2}$ & $r_{t}^{3}$ & $r_{t}^{4}$ \\
\hline \multicolumn{13}{|l|}{$t=1990$} \\
\hline all $^{a}$ & 0.09 & 0.50 & 0.29 & 0.12 & 0.04 & 0.58 & 0.32 & 0.07 & 0.43 & 1.15 & 1.11 & 0.53 \\
\hline non-employed lone mother, 1 child $0-6$ years & 0.25 & 0.64 & 0.09 & 0.01 & 0.17 & 0.80 & 0.03 & 0.00 & 0.66 & 1.24 & 0.35 & 0.03 \\
\hline non-employed lone mother, 3 children & 0.43 & 0.53 & 0.04 & 0.00 & 0.40 & 0.60 & 0.01 & 0.00 & 0.93 & 1.13 & 0.15 & 0.01 \\
\hline lone mother, 2 children & 0.14 & 0.66 & 0.17 & 0.02 & 0.06 & 0.83 & 0.11 & 0.00 & 0.42 & 1.26 & 0.61 & 0.09 \\
\hline unemployed lone mother, 2 children & 0.44 & 0.52 & 0.04 & 0.00 & 0.42 & 0.58 & 0.00 & 0.00 & 0.94 & 1.11 & 0.14 & 0.01 \\
\hline single men & 0.04 & 0.53 & 0.33 & 0.10 & 0.01 & 0.59 & 0.37 & 0.03 & 0.14 & 1.12 & 1.11 & 0.30 \\
\hline double income no kids & 0.01 & 0.35 & 0.42 & 0.22 & 0.00 & 0.30 & 0.57 & 0.13 & 0.04 & 0.86 & 1.35 & 0.60 \\
\hline double income, 2 children & 0.02 & 0.44 & 0.39 & 0.15 & 0.00 & 0.44 & 0.49 & 0.07 & 0.08 & 1.00 & 1.26 & 0.45 \\
\hline double income no kids, both high-skilled & 0.00 & 0.03 & 0.20 & 0.77 & 0.00 & 0.00 & 0.13 & 0.86 & 0.00 & 0.11 & 0.68 & 1.11 \\
\hline 1 employed adult, 1 unemployed adult & 0.09 & 0.63 & 0.24 & 0.04 & 0.02 & 0.77 & 0.20 & 0.01 & 0.28 & 1.23 & 0.82 & 0.15 \\
\hline double income no kids, both $42-64$ years & 0.01 & 0.28 & 0.43 & 0.28 & 0.00 & 0.21 & 0.59 & 0.20 & 0.02 & 0.75 & 1.37 & 0.71 \\
\hline 'couple with children' $b$ & 0.13 & 0.66 & 0.19 & 0.03 & 0.05 & 0.82 & 0.13 & 0.00 & 0.38 & 1.25 & 0.66 & 0.10 \\
\hline 'couple with children' ${ }^{, b}$, non-German & 0.18 & 0.66 & 0.14 & 0.02 & 0.10 & 0.84 & 0.07 & 0.00 & 0.52 & 1.26 & 0.49 & 0.06 \\
\hline 'couple with children' $b$, both children 6-11 years & 0.13 & 0.66 & 0.19 & 0.03 & 0.05 & 0.83 & 0.12 & 0.00 & 0.39 & 1.25 & 0.65 & 0.10 \\
\hline 'couple with children', ${ }^{\prime}$, earner low-skilled & 0.17 & 0.67 & 0.15 & 0.02 & 0.08 & 0.84 & 0.08 & 0.00 & 0.49 & 1.26 & 0.53 & 0.06 \\
\hline 'couple with children', ${ }^{b}$ earner unemployed & 0.41 & 0.54 & 0.04 & 0.00 & 0.38 & 0.62 & 0.01 & 0.00 & 0.91 & 1.14 & 0.16 & 0.01 \\
\hline 'couple with children' $b, 2$ earners & 0.04 & 0.52 & 0.34 & 0.10 & 0.00 & 0.58 & 0.38 & 0.03 & 0.13 & 1.11 & 1.12 & 0.32 \\
\hline 'couple with children' ${ }^{b}$, adults $42-64$ years & 0.09 & 0.63 & 0.23 & 0.04 & 0.03 & 0.78 & 0.19 & 0.01 & 0.29 & 1.23 & 0.80 & 0.14 \\
\hline 2 pensioners, 65 years or over & 0.05 & 0.56 & 0.31 & 0.08 & 0.01 & 0.65 & 0.32 & 0.02 & 0.17 & 1.16 & 1.03 & 0.25 \\
\hline 2 pensioners, 65 years or over, high-skilled & 0.00 & 0.08 & 0.32 & 0.60 & 0.00 & 0.02 & 0.33 & 0.65 & 0.00 & 0.27 & 1.05 & 1.07 \\
\hline 2 pensioners, 65 years or over, low-skilled & 0.25 & 0.65 & 0.10 & 0.01 & 0.16 & 0.81 & 0.04 & 0.00 & 0.65 & 1.24 & 0.36 & 0.03 \\
\hline single male pensioner, 65 years or over & 0.08 & 0.62 & 0.26 & 0.05 & 0.02 & 0.75 & 0.22 & 0.01 & 0.25 & 1.22 & 0.87 & 0.17 \\
\hline single female pensioner, 65 years or over & 0.10 & 0.64 & 0.22 & 0.04 & 0.03 & 0.79 & 0.17 & 0.00 & 0.31 & 1.24 & 0.76 & 0.13 \\
\hline \multicolumn{13}{|l|}{$t=1998$} \\
\hline all $^{a}$ & 0.07 & 0.51 & 0.30 & 0.12 & 0.02 & 0.59 & 0.33 & 0.05 & 0.30 & 1.16 & 1.12 & 0.42 \\
\hline non-employed lone mother, 1 child $0-6$ years & 0.24 & 0.67 & 0.08 & 0.01 & 0.14 & 0.84 & 0.02 & 0.00 & 0.59 & 1.25 & 0.25 & 0.01 \\
\hline non-employed lone mother, 3 children & 0.27 & 0.65 & 0.07 & 0.00 & 0.18 & 0.81 & 0.01 & 0.00 & 0.66 & 1.23 & 0.20 & 0.01 \\
\hline lone mother, 2 children & 0.07 & 0.64 & 0.25 & 0.04 & 0.01 & 0.79 & 0.20 & 0.00 & 0.17 & 1.22 & 0.79 & 0.10 \\
\hline unemployed lone mother, 2 children & 0.33 & 0.62 & 0.05 & 0.00 & 0.25 & 0.74 & 0.01 & 0.00 & 0.76 & 1.20 & 0.14 & 0.00 \\
\hline double income, 2 children & 0.01 & 0.39 & 0.43 & 0.17 & 0.00 & 0.34 & 0.58 & 0.08 & 0.02 & 0.89 & 1.34 & 0.44 \\
\hline double income no kids, both high-skilled & 0.00 & 0.12 & 0.39 & 0.50 & 0.00 & 0.04 & 0.47 & 0.49 & 0.00 & 0.30 & 1.21 & 1.00 \\
\hline 1 employed adult, 1 unemployed adult & 0.09 & 0.68 & 0.20 & 0.03 & 0.02 & 0.85 & 0.13 & 0.00 & 0.24 & 1.25 & 0.64 & 0.06 \\
\hline double income no kids, both $42-64$ years & 0.00 & 0.26 & 0.45 & 0.28 & 0.00 & 0.17 & 0.64 & 0.19 & 0.01 & 0.65 & 1.41 & 0.68 \\
\hline 'couple with children' $b$ & 0.11 & 0.69 & 0.19 & 0.02 & 0.03 & 0.86 & 0.11 & 0.00 & 0.28 & 1.26 & 0.58 & 0.05 \\
\hline 'couple with children', ${ }^{\prime}$, non-German & 0.16 & 0.70 & 0.13 & 0.01 & 0.07 & 0.88 & 0.05 & 0.00 & 0.42 & 1.26 & 0.39 & 0.02 \\
\hline 'couple with children', ${ }^{,}$, both children $6-11$ years & 0.08 & 0.66 & 0.23 & 0.03 & 0.02 & 0.82 & 0.16 & 0.00 & 0.20 & 1.24 & 0.72 & 0.08 \\
\hline 'couple with children' $b$, earner high-skilled & 0.05 & 0.60 & 0.30 & 0.06 & 0.01 & 0.71 & 0.27 & 0.01 & 0.12 & 1.18 & 0.93 & 0.14 \\
\hline 'couple with children', ${ }^{\prime}$, earner low-skilled & 0.16 & 0.70 & 0.13 & 0.01 & 0.07 & 0.88 & 0.05 & 0.00 & 0.42 & 1.26 & 0.40 & 0.02 \\
\hline 'couple with children', ${ }^{,}$, earner unemployed & 0.43 & 0.54 & 0.03 & 0.00 & 0.39 & 0.61 & 0.00 & 0.00 & 0.92 & 1.12 & 0.08 & 0.00 \\
\hline 'couple with children',, 2 earners & 0.02 & 0.47 & 0.39 & 0.12 & 0.00 & 0.48 & 0.48 & 0.04 & 0.04 & 1.03 & 1.23 & 0.31 \\
\hline 'couple with children' $b$, adults $42-64$ years & 0.04 & 0.56 & 0.33 & 0.07 & 0.00 & 0.65 & 0.34 & 0.01 & 0.09 & 1.14 & 1.03 & 0.19 \\
\hline 2 pensioners, 65 years or over & 0.03 & 0.54 & 0.35 & 0.08 & 0.00 & 0.60 & 0.38 & 0.02 & 0.07 & 1.11 & 1.09 & 0.22 \\
\hline 2 pensioners, 65 years or over, high-skilled & 0.00 & 0.05 & 0.27 & 0.68 & 0.00 & 0.01 & 0.23 & 0.77 & 0.00 & 0.12 & 0.85 & 1.12 \\
\hline 2 pensioners, 65 years or over, low-skilled & 0.17 & 0.69 & 0.12 & 0.01 & 0.08 & 0.88 & 0.04 & 0.00 & 0.45 & 1.26 & 0.37 & 0.02 \\
\hline single male pensioner, 65 years or over & 0.06 & 0.63 & 0.27 & 0.04 & 0.01 & 0.76 & 0.22 & 0.01 & 0.15 & 1.21 & 0.83 & 0.11 \\
\hline single female pensioner, 65 years or over & 0.08 & 0.67 & 0.22 & 0.03 & 0.02 & 0.83 & 0.15 & 0.00 & 0.22 & 1.24 & 0.68 & 0.07 \\
\hline
\end{tabular}

Note: unless indicated otherwise, households are German, adults are 18-41 years old, medium-skilled and employed, children are 6-11 years old,

and pensioners are medium-skilled; all numbers are based on estimates of specification (S3)

$P_{t}^{m}$ is the proportion of individuals in the $m$-th income class, $m=1 \ldots 4$

$P_{t}^{m, p}$ is the proportion of individuals with permanent income in the $m$-th income class

$r_{t}^{m}=P_{t}^{m, p} / P_{t}^{m}$ is the proportion of individuals in the $m$-th income class who will be there in the long run

$m=1$ denotes $0-0.5$ times mean income, $m=2$ denotes $0.5-1, m=3$ denotes $1-1.5$ and $m=4$ means over 1.5 times mean income

$a$ This corresponds to the case with no covariates

$b$ 'Couple with children' $=2$ adults, one employed, the other non-employed, 1 child 6-11, 1 child 12-17 
Table 6. Mobility measures, West Germany, sample $1990-98$

\begin{tabular}{|c|c|c|c|c|c|c|}
\hline Subgroup & $P_{t, t-1}^{1 \mid 1}$ & $P_{t, t-1}^{2 \mid 2}$ & $P_{t, t-1}^{3 \mid 3}$ & $P_{t, t-1}^{4 \mid 4}$ & $E_{t}$ & $M_{t, t-1}$ \\
\hline \multicolumn{7}{|l|}{$t=1991$} \\
\hline all & 0.466 & 0.713 & 0.504 & 0.535 & 0.534 & 0.594 \\
\hline non-employed lone mother, 1 child $0-6$ years & 0.598 & 0.766 & 0.295 & 0.128 & 0.402 & 0.737 \\
\hline non-employed lone mother, 3 children & 0.793 & 0.623 & 0.151 & 0.047 & 0.207 & 0.795 \\
\hline lone mother, 2 children & 0.537 & 0.786 & 0.333 & 0.158 & 0.463 & 0.728 \\
\hline unemployed lone mother, 2 children & 0.712 & 0.702 & 0.221 & 0.081 & 0.288 & 0.761 \\
\hline single men & 0.254 & 0.708 & 0.529 & 0.401 & 0.746 & 0.703 \\
\hline double income no kids & 0.155 & 0.588 & 0.564 & 0.550 & 0.845 & 0.715 \\
\hline double income, 2 children & 0.210 & 0.663 & 0.549 & 0.461 & 0.790 & 0.706 \\
\hline double income no kids, both high-skilled & 0.048 & 0.318 & 0.489 & 0.841 & 0.952 & 0.768 \\
\hline 1 employed adult, 1 unemployed adult & 0.273 & 0.728 & 0.522 & 0.380 & 0.727 & 0.699 \\
\hline double income no kids, both $42-64$ years & 0.130 & 0.543 & 0.564 & 0.598 & 0.870 & 0.721 \\
\hline 'couple with children' $a$ & 0.423 & 0.788 & 0.422 & 0.238 & 0.577 & 0.710 \\
\hline 'couple with children' ${ }^{a}$, non-German & 0.455 & 0.791 & 0.404 & 0.217 & 0.545 & 0.711 \\
\hline 'couple with children' ${ }^{a}$, both children 6-11 years & 0.454 & 0.791 & 0.398 & 0.214 & 0.546 & 0.714 \\
\hline 'couple with children' ${ }^{a}$, earner high-skilled & 0.291 & 0.732 & 0.506 & 0.362 & 0.709 & 0.703 \\
\hline 'couple with children' $a$, earner low-skilled & 0.493 & 0.791 & 0.372 & 0.189 & 0.507 & 0.719 \\
\hline 'couple with children' ${ }^{a}$, earner unemployed & 0.608 & 0.764 & 0.307 & 0.135 & 0.392 & 0.729 \\
\hline 'couple with children' ${ }^{a}, 2$ earners & 0.251 & 0.705 & 0.531 & 0.406 & 0.749 & 0.703 \\
\hline 'couple with children' ${ }^{\prime}$, adults $42-64$ years & 0.335 & 0.762 & 0.483 & 0.314 & 0.665 & 0.702 \\
\hline 2 pensioners, 65 years or over & 0.267 & 0.720 & 0.523 & 0.386 & 0.733 & 0.702 \\
\hline 2 pensioners, 65 years or over, high-skilled & 0.023 & 0.221 & 0.400 & 0.883 & 0.977 & 0.825 \\
\hline 2 pensioners, 65 years or over, low-skilled & 0.529 & 0.786 & 0.351 & 0.170 & 0.471 & 0.721 \\
\hline single male pensioner, 65 years or over & 0.323 & 0.756 & 0.490 & 0.325 & 0.677 & 0.702 \\
\hline single female pensioner, 65 years or over & 0.444 & 0.790 & 0.403 & 0.220 & 0.556 & 0.714 \\
\hline \multicolumn{7}{|l|}{$t=1998$} \\
\hline all & 0.550 & 0.746 & 0.545 & 0.596 & 0.450 & 0.521 \\
\hline non-employed lone mother, 1 child $0-6$ years & 0.632 & 0.782 & 0.370 & 0.209 & 0.368 & 0.669 \\
\hline non-employed lone mother, 3 children & 0.603 & 0.789 & 0.405 & 0.242 & 0.397 & 0.653 \\
\hline lone mother, 2 children & 0.393 & 0.768 & 0.531 & 0.413 & 0.607 & 0.632 \\
\hline unemployed lone mother, 2 children & 0.644 & 0.776 & 0.376 & 0.214 & 0.356 & 0.663 \\
\hline single men & 0.375 & 0.753 & 0.537 & 0.430 & 0.625 & 0.635 \\
\hline double income no kids & 0.259 & 0.657 & 0.578 & 0.569 & 0.741 & 0.646 \\
\hline double income, 2 children & 0.252 & 0.653 & 0.580 & 0.574 & 0.748 & 0.647 \\
\hline double income no kids, both high-skilled & 0.179 & 0.534 & 0.576 & 0.720 & 0.821 & 0.664 \\
\hline 1 employed adult, 1 unemployed adult & 0.477 & 0.793 & 0.479 & 0.331 & 0.523 & 0.640 \\
\hline double income no kids, both $42-64$ years & 0.223 & 0.609 & 0.582 & 0.625 & 0.777 & 0.654 \\
\hline 'couple with children' ${ }^{a}$ & 0.484 & 0.794 & 0.476 & 0.326 & 0.516 & 0.640 \\
\hline 'couple with children' ${ }^{a}$, non-German & 0.505 & 0.798 & 0.471 & 0.317 & 0.495 & 0.636 \\
\hline 'couple with children' ${ }^{\prime}$, both children 6-11 years & 0.432 & 0.782 & 0.509 & 0.375 & 0.568 & 0.634 \\
\hline 'couple with children' ${ }^{a}$, earner high-skilled & 0.420 & 0.773 & 0.512 & 0.385 & 0.580 & 0.636 \\
\hline 'couple with children' ${ }^{a}$, earner low-skilled & 0.544 & 0.798 & 0.437 & 0.278 & 0.456 & 0.648 \\
\hline 'couple with children' ${ }^{a}$, earner unemployed & 0.727 & 0.731 & 0.304 & 0.154 & 0.273 & 0.694 \\
\hline 'couple with children' ${ }^{a}, 2$ earners & 0.288 & 0.692 & 0.572 & 0.527 & 0.712 & 0.640 \\
\hline 'couple with children' ${ }^{a}$, adults $42-64$ years & 0.334 & 0.732 & 0.557 & 0.473 & 0.666 & 0.634 \\
\hline 2 pensioners, 65 years or over & 0.358 & 0.742 & 0.545 & 0.449 & 0.642 & 0.635 \\
\hline 2 pensioners, 65 years or over, high-skilled & 0.118 & 0.424 & 0.538 & 0.825 & 0.882 & 0.698 \\
\hline 2 pensioners, 65 years or over, low-skilled & 0.548 & 0.797 & 0.437 & 0.277 & 0.452 & 0.647 \\
\hline single male pensioner, 65 years or over & 0.431 & 0.779 & 0.507 & 0.374 & 0.569 & 0.637 \\
\hline single female pensioner, 65 years or over & 0.561 & 0.802 & 0.414 & 0.260 & 0.439 & 0.654 \\
\hline
\end{tabular}

Note: unless indicated otherwise, households are German, adults are 18-41 years old, medium-skilled and employed, children are 6-11 years old, and pensioners are medium-skilled; all numbers are based on estimates of specification (S3) $P_{t, t-1}^{m \mid m}$ is the probability of staying in the $m$-th income class from $t-1$ to $t$

$E_{t}=1-P_{t, t-1}^{1 \mid 1}$ is the poverty exit rate

$M_{t, t-1}=\left(4-\sum P_{t, t-1}^{m \mid m}\right) / 3$ is the Prais mobility index

$m=1$ denotes $0-0.5$ times mean income, $m=2$ means $0.5-1, m=3$ means $1-1.5$ and $m=4$ is over 1.5 times mean income

$a$ 'Couple with children' $=2$ adults, one employed, the other non-employed, 1 child $6-11,1$ child 12-17 
Table 7. Empirical variance covariance matrix of log equivalent income, East Germany, 1990 - 98, no covariates

(standard errors in parentheses ${ }^{a}$ )

\begin{tabular}{|c|c|c|c|c|c|c|c|c|c|}
\hline Year & 1990 & 1991 & 1992 & 1993 & 1994 & 1995 & 1996 & 1997 & 1998 \\
\hline 1990 & $\begin{array}{r}0.1201 \\
(0.0058)\end{array}$ & & & & & & & & \\
\hline 1991 & $\begin{array}{r}0.0728 \\
(0.0052)\end{array}$ & $\begin{array}{r}0.1389 \\
(0.0093)\end{array}$ & & & & & & & \\
\hline 1992 & $\begin{array}{r}0.0632 \\
(0.0056)\end{array}$ & $\begin{array}{r}0.0933 \\
(0.0062)\end{array}$ & $\begin{array}{r}0.1386 \\
(0.0083)\end{array}$ & & & & & & \\
\hline 1993 & $\begin{array}{r}0.0616 \\
(0.0052)\end{array}$ & $\begin{array}{r}0.0747 \\
(0.0059)\end{array}$ & $\begin{array}{r}0.0976 \\
(0.0074)\end{array}$ & $\begin{array}{r}0.1382 \\
(0.0091)\end{array}$ & & & & & \\
\hline 1994 & $\begin{array}{r}0.0568 \\
(0.0048)\end{array}$ & $\begin{array}{r}0.0738 \\
(0.0057)\end{array}$ & $\begin{array}{r}0.0900 \\
(0.0061)\end{array}$ & $\begin{array}{r}0.0990 \\
(0.0062)\end{array}$ & $\begin{array}{r}0.1380 \\
(0.0084)\end{array}$ & & & & \\
\hline 1995 & $\begin{array}{r}0.0545 \\
(0.0045)\end{array}$ & $\begin{array}{r}0.0666 \\
(0.0045)\end{array}$ & $\begin{array}{r}0.0799 \\
(0.0056)\end{array}$ & $\begin{array}{r}0.0918 \\
(0.0061)\end{array}$ & $\begin{array}{r}0.0987 \\
(0.0061)\end{array}$ & $\begin{array}{r}0.1378 \\
(0.0092)\end{array}$ & & & \\
\hline 1996 & $\begin{array}{r}0.0487 \\
(0.0047)\end{array}$ & $\begin{array}{r}0.0525 \\
(0.0050)\end{array}$ & $\begin{array}{r}0.0644 \\
(0.0055)\end{array}$ & $\begin{array}{r}0.0766 \\
(0.0051)\end{array}$ & $\begin{array}{r}0.0805 \\
(0.0051)\end{array}$ & $\begin{array}{r}0.0929 \\
(0.0051)\end{array}$ & $\begin{array}{r}0.1258 \\
(0.0063)\end{array}$ & & \\
\hline 1997 & $\begin{array}{r}0.0459 \\
(0.0045)\end{array}$ & $\begin{array}{r}0.0522 \\
(0.0043)\end{array}$ & $\begin{array}{r}0.0643 \\
(0.0056)\end{array}$ & $\begin{array}{r}0.0747 \\
(0.0058)\end{array}$ & $\begin{array}{r}0.0782 \\
(0.0059)\end{array}$ & $\begin{array}{r}0.0893 \\
(0.0059)\end{array}$ & $\begin{array}{r}0.0917 \\
(0.0053)\end{array}$ & $\begin{array}{r}0.1276 \\
(0.0071)\end{array}$ & \\
\hline 1998 & $\begin{array}{r}0.0449 \\
(0.0040)\end{array}$ & $\begin{array}{r}0.0514 \\
(0.0048)\end{array}$ & $\begin{array}{r}0.0602 \\
(0.0048)\end{array}$ & $\begin{array}{r}0.0736 \\
(0.0049)\end{array}$ & $\begin{array}{r}0.0775 \\
(0.0049)\end{array}$ & $\begin{array}{r}0.0857 \\
(0.0050)\end{array}$ & $\begin{array}{r}0.0865 \\
(0.0046)\end{array}$ & $\begin{array}{r}0.0981 \\
(0.0056)\end{array}$ & $\begin{array}{r}0.1279 \\
(0.0067)\end{array}$ \\
\hline
\end{tabular}

${ }^{a}$ Standard errors account for household clustering

Table 8. Empirical variance covariance matrix of log equivalent income, East Germany, 1990 - 98, with covariates (standard errors in parentheses ${ }^{a}$ )

\begin{tabular}{|c|c|c|c|c|c|c|c|c|c|}
\hline Year & 1990 & 1991 & 1992 & 1993 & 1994 & 1995 & 1996 & 1997 & 1998 \\
\hline 1990 & $\begin{array}{r}0.0579 \\
(0.0030)\end{array}$ & & & & & & & & \\
\hline 1991 & $\begin{array}{r}0.0295 \\
(0.0028)\end{array}$ & $\begin{array}{r}0.0902 \\
(0.0084)\end{array}$ & & & & & & & \\
\hline 1992 & $\begin{array}{r}0.0234 \\
(0.0026)\end{array}$ & $\begin{array}{r}0.0409 \\
(0.0046)\end{array}$ & $\begin{array}{r}0.0793 \\
(0.0058)\end{array}$ & & & & & & \\
\hline 1993 & $\begin{array}{r}0.0209 \\
(0.0024)\end{array}$ & $\begin{array}{r}0.0294 \\
(0.0034)\end{array}$ & $\begin{array}{r}0.0387 \\
(0.0038)\end{array}$ & $\begin{array}{r}0.0729 \\
(0.0054)\end{array}$ & & & & & \\
\hline 1994 & $\begin{array}{r}0.0200 \\
(0.0025)\end{array}$ & $\begin{array}{r}0.0303 \\
(0.0038)\end{array}$ & $\begin{array}{r}0.0365 \\
(0.0039)\end{array}$ & $\begin{array}{r}0.0389 \\
(0.0031)\end{array}$ & $\begin{array}{r}0.0765 \\
(0.0055)\end{array}$ & & & & \\
\hline 1995 & $\begin{array}{r}0.0202 \\
(0.0023)\end{array}$ & $\begin{array}{r}0.0271 \\
(0.0034)\end{array}$ & $\begin{array}{r}0.0336 \\
(0.0035)\end{array}$ & $\begin{array}{r}0.0361 \\
(0.0033)\end{array}$ & $\begin{array}{r}0.0438 \\
(0.0036)\end{array}$ & $\begin{array}{r}0.0825 \\
(0.0065)\end{array}$ & & & \\
\hline 1996 & $\begin{array}{r}0.0165 \\
(0.0021)\end{array}$ & $\begin{array}{r}0.0223 \\
(0.0031)\end{array}$ & $\begin{array}{r}0.0234 \\
(0.0028)\end{array}$ & $\begin{array}{r}0.0293 \\
(0.0027)\end{array}$ & $\begin{array}{r}0.0317 \\
(0.0030)\end{array}$ & $\begin{array}{r}0.0458 \\
(0.0033)\end{array}$ & $\begin{array}{r}0.0796 \\
(0.0051)\end{array}$ & & \\
\hline 1997 & $\begin{array}{r}0.0134 \\
(0.0021)\end{array}$ & $\begin{array}{r}0.0196 \\
(0.0028)\end{array}$ & $\begin{array}{r}0.0229 \\
(0.0029)\end{array}$ & $\begin{array}{r}0.0251 \\
(0.0030)\end{array}$ & $\begin{array}{r}0.0304 \\
(0.0037)\end{array}$ & $\begin{array}{r}0.0397 \\
(0.0036)\end{array}$ & $\begin{array}{r}0.0455 \\
(0.0032)\end{array}$ & $\begin{array}{r}0.0776 \\
(0.0052)\end{array}$ & \\
\hline 1998 & $\begin{array}{r}0.0144 \\
(0.0020)\end{array}$ & $\begin{array}{r}0.0216 \\
(0.0023)\end{array}$ & $\begin{array}{r}0.0209 \\
(0.0025)\end{array}$ & $\begin{array}{r}0.0259 \\
(0.0027)\end{array}$ & $\begin{array}{r}0.0292 \\
(0.0031)\end{array}$ & $\begin{array}{r}0.0380 \\
(0.0030)\end{array}$ & $\begin{array}{r}0.0416 \\
(0.0029)\end{array}$ & $\begin{array}{r}0.0479 \\
(0.0036)\end{array}$ & $\begin{array}{r}0.0778 \\
(0.0049)\end{array}$ \\
\hline
\end{tabular}

${ }^{a}$ Standard errors account for household clustering 
Table 9. Parameter estimates, East Germany, 1990 - 98 (standard errors in parentheses ${ }^{a}$ )

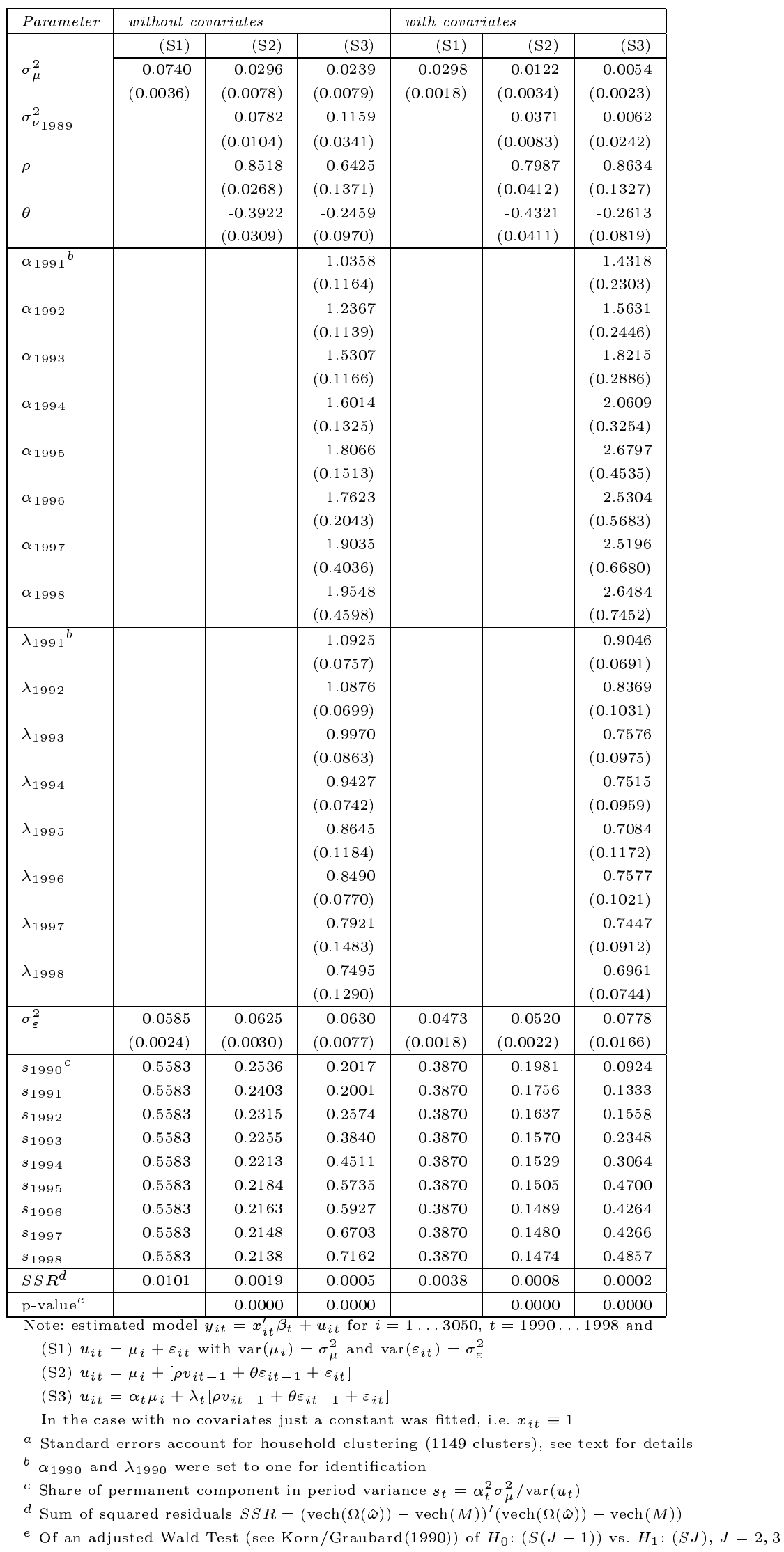


Table 10. Population shares of income classes, East Germany, sample $1990-98$

\begin{tabular}{|c|c|c|c|c|c|c|c|c|c|c|c|c|}
\hline Subgroup & $P_{t}^{1}$ & $P_{t}^{2}$ & $P_{t}^{3}$ & $P_{t}^{4}$ & $P_{t}^{1, p}$ & $P_{t}^{2, p}$ & $P_{t}^{3, p}$ & $P_{t}^{4, p}$ & $r_{t}^{1}$ & $r_{t}^{2}$ & $r_{t}^{3}$ & $r_{t}^{4}$ \\
\hline \multicolumn{13}{|l|}{$t=1990$} \\
\hline all $^{a}$ & 0.03 & 0.53 & 0.34 & 0.09 & 0.00 & 0.64 & 0.36 & 0.00 & 0.00 & 1.21 & 1.03 & 0.02 \\
\hline non-employed lone mother, 1 child $0-6$ years & 0.45 & 0.55 & 0.00 & 0.00 & 0.34 & 0.66 & 0.00 & 0.00 & 0.75 & 1.21 & 0.00 & 0.00 \\
\hline non-employed lone mother, 3 children & 0.55 & 0.44 & 0.00 & 0.00 & 0.67 & 0.33 & 0.00 & 0.00 & 1.21 & 0.74 & 0.00 & 0.00 \\
\hline lone mother, 2 children & 0.09 & 0.85 & 0.06 & 0.00 & 0.00 & 1.00 & 0.00 & 0.00 & 0.00 & 1.18 & 0.00 & 0.00 \\
\hline unemployed lone mother, 2 children & 0.13 & 0.83 & 0.04 & 0.00 & 0.00 & 1.00 & 0.00 & 0.00 & 0.00 & 1.20 & 0.00 & 0.00 \\
\hline single men & 0.03 & 0.80 & 0.17 & 0.00 & 0.00 & 1.00 & 0.00 & 0.00 & 0.00 & 1.25 & 0.01 & 0.00 \\
\hline double income, 2 children & 0.00 & 0.50 & 0.45 & 0.05 & 0.00 & 0.51 & 0.49 & 0.00 & 0.00 & 1.02 & 1.09 & 0.00 \\
\hline double income no kids, both high-skilled & 0.00 & 0.08 & 0.53 & 0.39 & 0.00 & 0.00 & 0.82 & 0.18 & 0.00 & 0.00 & 1.55 & 0.46 \\
\hline 1 employed adult, 1 unemployed adult & 0.00 & 0.50 & 0.46 & 0.05 & 0.00 & 0.49 & 0.51 & 0.00 & 0.00 & 0.99 & 1.12 & 0.00 \\
\hline double income no kids, both $42-64$ years & 0.00 & 0.36 & 0.54 & 0.09 & 0.00 & 0.13 & 0.87 & 0.00 & 0.00 & 0.35 & 1.60 & 0.00 \\
\hline 'couple with children' ${ }^{b}$ & 0.09 & 0.85 & 0.07 & 0.00 & 0.00 & 1.00 & 0.00 & 0.00 & 0.00 & 1.18 & 0.00 & 0.00 \\
\hline 'couple with children', ${ }^{\prime}$, non-German & 0.02 & 0.77 & 0.20 & 0.01 & 0.00 & 1.00 & 0.00 & 0.00 & 0.00 & 1.29 & 0.02 & 0.00 \\
\hline 'couple with children' $b$, both children $6-11$ years & 0.09 & 0.85 & 0.06 & 0.00 & 0.00 & 1.00 & 0.00 & 0.00 & 0.00 & 1.18 & 0.00 & 0.00 \\
\hline 'couple with children', ${ }^{, b}$ earner low-skilled & 0.09 & 0.85 & 0.07 & 0.00 & 0.00 & 1.00 & 0.00 & 0.00 & 0.00 & 1.18 & 0.00 & 0.00 \\
\hline 'couple with children', & 0.13 & 0.83 & 0.04 & 0.00 & 0.00 & 1.00 & 0.00 & 0.00 & 0.00 & 1.20 & 0.00 & 0.00 \\
\hline 'couple with children' $b, 2$ earners & 0.00 & 0.60 & 0.30 & 0.00 & 0.00 & 0.80 & 0.20 & 0.00 & 0.00 & 1.30 & 0.50 & 0.00 \\
\hline 'couple with children' ${ }^{\prime}$, adults $42-64$ years & 0.13 & 0.83 & 0.04 & 0.00 & 0.00 & 1.00 & 0.00 & 0.00 & 0.00 & 1.20 & 0.00 & 0.00 \\
\hline 2 pensioners, 65 years or over & 0.09 & 0.85 & 0.06 & 0.00 & 0.00 & 1.00 & 0.00 & 0.00 & 0.00 & 1.18 & 0.00 & 0.00 \\
\hline 2 pensioners, 65 years or over, high-skilled & 0.00 & 0.61 & 0.36 & 0.02 & 0.00 & 0.83 & 0.17 & 0.00 & 0.00 & 1.36 & 0.46 & 0.00 \\
\hline 2 pensioners, 65 years or over, low-skilled & 0.37 & 0.62 & 0.01 & 0.00 & 0.14 & 0.86 & 0.00 & 0.00 & 0.38 & 1.38 & 0.00 & 0.00 \\
\hline single male pensioner, 65 years or over & 0.15 & 0.82 & 0.03 & 0.00 & 0.00 & 1.00 & 0.00 & 0.00 & 0.00 & 1.22 & 0.00 & 0.00 \\
\hline single female pensioner, 65 years or over & 0.16 & 0.81 & 0.03 & 0.00 & 0.00 & 1.00 & 0.00 & 0.00 & 0.00 & 1.24 & 0.00 & 0.00 \\
\hline \multicolumn{13}{|l|}{$t=1998$} \\
\hline all $^{a}$ & 0.04 & 0.53 & 0.34 & 0.10 & 0.02 & 0.56 & 0.36 & 0.06 & 0.48 & 1.06 & 1.07 & 0.64 \\
\hline non-employed lone mother, 1 child $0-6$ years & 0.16 & 0.77 & 0.06 & 0.00 & 0.08 & 0.91 & 0.02 & 0.00 & 0.48 & 1.17 & 0.24 & 0.01 \\
\hline non-employed lone mother, moved to West & 0.06 & 0.77 & 0.16 & 0.01 & 0.01 & 0.90 & 0.09 & 0.00 & 0.22 & 1.17 & 0.53 & 0.03 \\
\hline non-employed lone mother, 3 children & 0.38 & 0.61 & 0.01 & 0.00 & 0.33 & 0.67 & 0.00 & 0.00 & 0.87 & 1.10 & 0.06 & 0.00 \\
\hline lone mother, 2 children & 0.09 & 0.79 & 0.12 & 0.00 & 0.03 & 0.92 & 0.05 & 0.00 & 0.30 & 1.18 & 0.41 & 0.02 \\
\hline double income no kids & 0.00 & 0.41 & 0.48 & 0.11 & 0.00 & 0.37 & 0.59 & 0.04 & 0.01 & 0.91 & 1.23 & 0.35 \\
\hline double income no kids, moved to West & 0.00 & 0.22 & 0.53 & 0.25 & 0.00 & 0.13 & 0.70 & 0.16 & 0.00 & 0.61 & 1.32 & 0.66 \\
\hline double income, 2 children & 0.01 & 0.52 & 0.41 & 0.06 & 0.00 & 0.54 & 0.45 & 0.01 & 0.03 & 1.04 & 1.09 & 0.23 \\
\hline double income no kids, both high-skilled & 0.00 & 0.13 & 0.50 & 0.37 & 0.00 & 0.05 & 0.63 & 0.32 & 0.00 & 0.40 & 1.26 & 0.86 \\
\hline 1 employed adult, 1 unemployed adult & 0.05 & 0.76 & 0.18 & 0.01 & 0.01 & 0.89 & 0.10 & 0.00 & 0.20 & 1.17 & 0.56 & 0.04 \\
\hline double income no kids, both $42-64$ years & 0.00 & 0.35 & 0.51 & 0.14 & 0.00 & 0.29 & 0.65 & 0.06 & 0.01 & 0.83 & 1.27 & 0.44 \\
\hline 'couple with children' $b$ & 0.07 & 0.77 & 0.15 & 0.01 & 0.02 & 0.91 & 0.08 & 0.00 & 0.24 & 1.17 & 0.50 & 0.03 \\
\hline 'couple with children' ${ }^{\prime}$, moved to West & 0.02 & 0.65 & 0.30 & 0.03 & 0.00 & 0.74 & 0.26 & 0.00 & 0.08 & 1.13 & 0.86 & 0.11 \\
\hline 'couple with children' $b$, non-German & 0.25 & 0.71 & 0.03 & 0.00 & 0.17 & 0.83 & 0.00 & 0.00 & 0.67 & 1.16 & 0.13 & 0.00 \\
\hline 'couple with children' ${ }^{b}$, both children 6-11 years & 0.08 & 0.78 & 0.13 & 0.01 & 0.02 & 0.92 & 0.06 & 0.00 & 0.28 & 1.18 & 0.44 & 0.02 \\
\hline 'couple with children', & 0.03 & 0.68 & 0.27 & 0.02 & 0.00 & 0.78 & 0.22 & 0.00 & 0.10 & 1.14 & 0.80 & 0.09 \\
\hline 'couple with children', ${ }^{\prime}$, earner low-skilled & 0.11 & 0.79 & 0.10 & 0.00 & 0.04 & 0.93 & 0.04 & 0.00 & 0.35 & 1.18 & 0.36 & 0.02 \\
\hline 'couple with children' ${ }^{b}$, earner unemployed & 0.35 & 0.63 & 0.02 & 0.00 & 0.30 & 0.70 & 0.00 & 0.00 & 0.83 & 1.12 & 0.07 & 0.00 \\
\hline 'couple with children' ${ }^{\prime}, 2$ earners & 0.01 & 0.59 & 0.35 & 0.04 & 0.00 & 0.64 & 0.35 & 0.01 & 0.05 & 1.09 & 0.98 & 0.16 \\
\hline 'couple with children' ${ }^{\prime}$, adults $42-64$ years & 0.04 & 0.73 & 0.22 & 0.01 & 0.01 & 0.85 & 0.15 & 0.00 & 0.15 & 1.16 & 0.67 & 0.06 \\
\hline 2 pensioners, 65 years or over & 0.01 & 0.49 & 0.43 & 0.07 & 0.00 & 0.50 & 0.48 & 0.02 & 0.03 & 1.01 & 1.13 & 0.25 \\
\hline 2 pensioners, 65 years or over, now West & 0.00 & 0.29 & 0.53 & 0.18 & 0.00 & 0.21 & 0.69 & 0.10 & 0.01 & 0.74 & 1.31 & 0.53 \\
\hline 2 pensioners, 65 years or over, high-skilled & 0.00 & 0.31 & 0.52 & 0.17 & 0.00 & 0.24 & 0.68 & 0.08 & 0.01 & 0.77 & 1.30 & 0.50 \\
\hline 2 pensioners, 65 years or over, low-skilled & 0.02 & 0.62 & 0.32 & 0.03 & 0.00 & 0.70 & 0.30 & 0.00 & 0.07 & 1.12 & 0.92 & 0.13 \\
\hline single male pensioner, 65 years or over & 0.03 & 0.70 & 0.25 & 0.02 & 0.00 & 0.81 & 0.18 & 0.00 & 0.12 & 1.15 & 0.74 & 0.07 \\
\hline single female pensioner, 65 years or over & 0.03 & 0.72 & 0.23 & 0.02 & 0.00 & 0.83 & 0.16 & 0.00 & 0.13 & 1.16 & 0.71 & 0.07 \\
\hline
\end{tabular}

Note: unless indicated otherwise, households are German, adults are 18-41 years old, medium-skilled and employed, children are 6-11 years old,

and pensioners are medium-skilled; all numbers are based on estimates of specification (S3)

$P_{t}^{m}$ is the proportion of individuals in the $m$-th income class, $m=1 \ldots 4$

$P_{t}^{m, p}$ is the proportion of individuals with permanent income in the $m$-th income class

$r_{t}^{m}=P_{t}^{m, p} / P_{t}^{m}$ is the proportion of individuals in the $m$-th income class who will be there in the long run

$m=1$ denotes $0-0.5$ times mean income, $m=2$ denotes $0.5-1, m=3$ denotes $1-1.5$ and $m=4$ means over 1.5 times mean income

${ }^{a}$ This corresponds to the case with no covariates

${ }^{b}$ 'Couple with children' $=2$ adults, one employed, the other non-employed, 1 child 6-11, 1 child 12-17 
Table 11. Mobility measures, East Germany, sample $1990-98$

\begin{tabular}{|c|c|c|c|c|c|c|}
\hline Subgroup & $P_{t, t-1}^{1 \mid 1}$ & $P_{t, t-1}^{2 \mid 2}$ & $P_{t, t-1}^{3 \mid 3}$ & $P_{t, t-1}^{4 \mid 4}$ & $E_{t}$ & $M_{t, t-1}$ \\
\hline \multicolumn{7}{|l|}{$t=1991$} \\
\hline all & 0.314 & 0.685 & 0.471 & 0.388 & 0.686 & 0.714 \\
\hline non-employed lone mother, 1 child $0-6$ years & 0.309 & 0.802 & 0.367 & 0.149 & 0.691 & 0.791 \\
\hline non-employed lone mother, 3 children & 0.491 & 0.744 & 0.229 & 0.068 & 0.509 & 0.823 \\
\hline lone mother, 2 children & 0.301 & 0.793 & 0.345 & 0.129 & 0.699 & 0.811 \\
\hline unemployed lone mother, 2 children & 0.681 & 0.627 & 0.093 & 0.017 & 0.319 & 0.861 \\
\hline single men & 0.178 & 0.724 & 0.461 & 0.227 & 0.822 & 0.803 \\
\hline double income no kids & 0.096 & 0.559 & 0.542 & 0.361 & 0.904 & 0.814 \\
\hline double income, 2 children & 0.135 & 0.639 & 0.508 & 0.286 & 0.865 & 0.811 \\
\hline double income no kids, both high-skilled & 0.020 & 0.254 & 0.489 & 0.681 & 0.980 & 0.852 \\
\hline 1 employed adult, 1 unemployed adult & 0.378 & 0.800 & 0.292 & 0.089 & 0.622 & 0.814 \\
\hline double income no kids, both $42-64$ years & 0.104 & 0.572 & 0.537 & 0.346 & 0.896 & 0.814 \\
\hline 'couple with children' ${ }^{a}$ & 0.202 & 0.761 & 0.438 & 0.206 & 0.798 & 0.797 \\
\hline 'couple with children' ${ }^{a}$, non-German & 0.540 & 0.764 & 0.169 & 0.038 & 0.460 & 0.830 \\
\hline 'couple with children' ${ }^{a}$, both children 6-11 years & 0.243 & 0.780 & 0.398 & 0.169 & 0.757 & 0.803 \\
\hline 'couple with children' $a$, earner high-skilled & 0.109 & 0.638 & 0.528 & 0.330 & 0.891 & 0.798 \\
\hline 'couple with children' ${ }^{a}$, earner low-skilled & 0.201 & 0.760 & 0.440 & 0.208 & 0.799 & 0.797 \\
\hline 'couple with children' ${ }^{a}$, earner unemployed & 0.564 & 0.716 & 0.154 & 0.035 & 0.436 & 0.844 \\
\hline 'couple with children' $a, 2$ earners & 0.150 & 0.668 & 0.492 & 0.262 & 0.850 & 0.809 \\
\hline 'couple with children' $a$, adults $42-64$ years & 0.228 & 0.779 & 0.415 & 0.185 & 0.772 & 0.797 \\
\hline 2 pensioners, 65 years or over & 0.187 & 0.752 & 0.454 & 0.223 & 0.813 & 0.795 \\
\hline 2 pensioners, 65 years or over, high-skilled & 0.058 & 0.485 & 0.558 & 0.458 & 0.942 & 0.813 \\
\hline 2 pensioners, 65 years or over, low-skilled & 0.177 & 0.770 & 0.485 & 0.267 & 0.823 & 0.768 \\
\hline single male pensioner, 65 years or over & 0.243 & 0.786 & 0.402 & 0.174 & 0.757 & 0.798 \\
\hline single female pensioner, 65 years or over & 0.237 & 0.785 & 0.409 & 0.180 & 0.763 & 0.796 \\
\hline \multicolumn{7}{|l|}{$t=1998$} \\
\hline all & 0.411 & 0.744 & 0.551 & 0.501 & 0.589 & 0.598 \\
\hline non-employed lone mother, 1 child $0-6$ years & 0.400 & 0.835 & 0.344 & 0.118 & 0.600 & 0.768 \\
\hline non-employed lone mother, moved to West Germany & 0.318 & 0.827 & 0.404 & 0.155 & 0.682 & 0.765 \\
\hline non-employed lone mother, 3 children & 0.630 & 0.739 & 0.176 & 0.041 & 0.370 & 0.805 \\
\hline lone mother, 2 children & 0.386 & 0.836 & 0.344 & 0.116 & 0.614 & 0.773 \\
\hline unemployed lone mother, 2 children & 0.659 & 0.716 & 0.157 & 0.034 & 0.341 & 0.811 \\
\hline single men & 0.253 & 0.792 & 0.464 & 0.204 & 0.747 & 0.762 \\
\hline double income no kids & 0.147 & 0.668 & 0.569 & 0.342 & 0.853 & 0.758 \\
\hline double income no kids, moved to West Germany & 0.113 & 0.590 & 0.599 & 0.438 & 0.887 & 0.753 \\
\hline double income, 2 children & 0.193 & 0.732 & 0.525 & 0.272 & 0.807 & 0.759 \\
\hline double income no kids, both high-skilled & 0.045 & 0.409 & 0.597 & 0.615 & 0.955 & 0.778 \\
\hline 1 employed adult, 1 unemployed adult & 0.339 & 0.830 & 0.383 & 0.140 & 0.661 & 0.769 \\
\hline double income no kids, both $42-64$ years & 0.105 & 0.599 & 0.599 & 0.417 & 0.895 & 0.760 \\
\hline 'couple with children' ${ }^{a}$ & 0.342 & 0.832 & 0.381 & 0.139 & 0.658 & 0.768 \\
\hline 'couple with children' ${ }^{a}$, moved to West Germany & 0.276 & 0.800 & 0.445 & 0.187 & 0.724 & 0.764 \\
\hline 'couple with children' $a$, non-German & 0.862 & 0.611 & 0.045 & 0.006 & 0.138 & 0.825 \\
\hline 'couple with children' ${ }^{a}$, both children 6-11 years & 0.382 & 0.836 & 0.346 & 0.117 & 0.618 & 0.773 \\
\hline 'couple with children' ${ }^{a}$, earner high-skilled & 0.230 & 0.782 & 0.486 & 0.226 & 0.770 & 0.759 \\
\hline 'couple with children' ${ }^{a}$, earner low-skilled & 0.313 & 0.833 & 0.420 & 0.169 & 0.687 & 0.755 \\
\hline 'couple with children' ${ }^{a}$, earner unemployed & 0.613 & 0.751 & 0.185 & 0.044 & 0.387 & 0.802 \\
\hline 'couple with children' $a, 2$ earners & 0.215 & 0.759 & 0.502 & 0.243 & 0.785 & 0.760 \\
\hline 'couple with children' $a$, adults $42-64$ years & 0.253 & 0.801 & 0.464 & 0.204 & 0.747 & 0.759 \\
\hline 2 pensioners, 65 years or over & 0.136 & 0.671 & 0.574 & 0.349 & 0.864 & 0.757 \\
\hline 2 pensioners, 65 years or over, now West Germany & 0.102 & 0.583 & 0.602 & 0.433 & 0.898 & 0.760 \\
\hline 2 pensioners, 65 years or over, high-skilled & 0.075 & 0.535 & 0.610 & 0.485 & 0.925 & 0.765 \\
\hline 2 pensioners, 65 years or over, low-skilled & 0.158 & 0.722 & 0.555 & 0.313 & 0.842 & 0.751 \\
\hline single male pensioner, 65 years or over & 0.247 & 0.795 & 0.470 & 0.209 & 0.753 & 0.760 \\
\hline single female pensioner, 65 years or over & 0.360 & 0.832 & 0.368 & 0.130 & 0.640 & 0.770 \\
\hline
\end{tabular}

Note: unless indicated otherwise, households are German, adults are 18-41 years old, medium-skilled and employed, children are 6-11 years old, and pensioners are medium-skilled; all numbers are based on estimates of specification (S3) $P_{t, t-1}^{m \mid m}$ is the probability of staying in the $m$-th income class from $t-1$ to $t$

$E_{t}=1-P_{t, t-1}^{1 \mid 1}$ is the poverty exit rate

$M_{t, t-1}=\left(4-\sum P_{t, t-1}^{m \mid m}\right) / 3$ is the Prais mobility index

$m=1$ denotes $0-0.5$ times mean income, $m=2$ means $0.5-1, m=3$ means $1-1.5$ and $m=4$ is over 1.5 times mean income

${ }^{a}$ 'Couple with children' $=2$ adults, one employed, the other non-employed, 1 child 6-11, 1 child 12-17 
Table A1. Parameter estimates, West Germany, 1990 - 98 standard errors based on independence assumption in parentheses ${ }^{a}$

\begin{tabular}{|c|c|c|c|c|c|c|}
\hline Parameter & without $c$ & ariates & & with cov & ates & \\
\hline & (S1) & (S2) & (S3) & (S1) & (S2) & (S3) \\
\hline$\sigma_{\mu}^{2}$ & $\begin{array}{r}0.1274 \\
(0.0047)\end{array}$ & $\begin{array}{r}0.1000 \\
(0.0146)\end{array}$ & $\begin{array}{r}0.1116 \\
(0.0109)\end{array}$ & $\begin{array}{r}0.0705 \\
(0.0029)\end{array}$ & $\begin{array}{r}0.0599 \\
(0.0041)\end{array}$ & $\begin{array}{r}0.0613 \\
(0.0080)\end{array}$ \\
\hline$\sigma_{\nu_{1989}}^{2}$ & & 0.1145 & 0.4263 & & 0.1117 & 0.6729 \\
\hline & & $(0.0245)$ & $(0.2480)$ & & $(0.0265)$ & $(0.7334)$ \\
\hline$\rho$ & & 0.7403 & 0.3581 & & 0.6265 & 0.2752 \\
\hline & & $(0.0989)$ & $(0.0966)$ & & $(0.0625)$ & $(0.1400)$ \\
\hline$\theta$ & & -0.2967 & -0.2793 & & -0.3041 & -0.3702 \\
\hline & & $(0.0654)$ & $(0.0301)$ & & $(0.0502)$ & $(0.0436)$ \\
\hline$\alpha_{1991}$ & & & 1.0018 & & & 0.9913 \\
\hline & & & $(0.0329)$ & & & $(0.0586)$ \\
\hline$\alpha_{1992}$ & & & 1.0536 & & & 1.0788 \\
\hline & & & $(0.0660)$ & & & $(0.0580)$ \\
\hline$\alpha_{1993}$ & & & 1.0579 & & & 1.0696 \\
\hline & & & $(0.0792)$ & & & $(0.0771)$ \\
\hline$\alpha_{1994}$ & & & 1.0514 & & & 1.0307 \\
\hline & & & $(0.0803)$ & & & $(0.0872)$ \\
\hline$\alpha_{1995}$ & & & 0.9924 & & & 0.9861 \\
\hline & & & $(0.0755)$ & & & $(0.0855)$ \\
\hline$\alpha_{1996}$ & & & 0.9688 & & & 0.9479 \\
\hline & & & $(0.0741)$ & & & $(0.0839)$ \\
\hline$\alpha_{1997}$ & & & 0.9194 & & & 0.9326 \\
\hline & & & $(0.0676)$ & & & $(0.0817)$ \\
\hline$\alpha_{1998}$ & & & 0.9000 & & & 0.8981 \\
\hline & & & $(0.0679)$ & & & $(0.0862)$ \\
\hline$\lambda_{1991}$ & & & 1.3582 & & & 1.5132 \\
\hline & & & $(0.1577)$ & & & $(0.3456)$ \\
\hline$\lambda_{1992}$ & & & 1.3187 & & & 1.4312 \\
\hline & & & $(0.1932)$ & & & $(0.3706)$ \\
\hline$\lambda_{1993}$ & & & 1.3813 & & & 1.5661 \\
\hline & & & $(0.2199)$ & & & $(0.4377)$ \\
\hline$\lambda_{1994}$ & & & 1.4385 & & & 1.6119 \\
\hline & & & $(0.2170)$ & & & $(0.4531)$ \\
\hline$\lambda_{1995}$ & & & 1.4802 & & & 1.6750 \\
\hline & & & $(0.2153)$ & & & $(0.4593)$ \\
\hline$\lambda_{1996}$ & & & 1.5171 & & & 1.7109 \\
\hline & & & $(0.2284)$ & & & $(0.4866)$ \\
\hline$\lambda_{1997}$ & & & 1.5263 & & & 1.6908 \\
\hline & & & $(0.2316)$ & & & $(0.4909)$ \\
\hline$\lambda_{1998}$ & & & 1.5629 & & & 1.7233 \\
\hline & & & $(0.2603)$ & & & $(0.5209)$ \\
\hline$\sigma_{\varepsilon}^{2}$ & 0.0541 & 0.0526 & 0.0277 & 0.0468 & 0.0457 & 0.0181 \\
\hline & $(0.0016)$ & $(0.0029)$ & $(0.0071)$ & $(0.0013)$ & $(0.0016)$ & $(0.0098)$ \\
\hline$s_{1990}$ & 0.7020 & 0.5078 & 0.5854 & 0.6013 & 0.4397 & 0.4745 \\
\hline$s_{1991}$ & 0.7020 & 0.5340 & 0.6377 & 0.6013 & 0.4895 & 0.5441 \\
\hline$s_{1992}$ & 0.7020 & 0.5495 & 0.6865 & 0.6013 & 0.5123 & 0.6270 \\
\hline$s_{1993}$ & 0.7020 & 0.5584 & 0.6743 & 0.6013 & 0.5219 & 0.5871 \\
\hline$s_{1994}$ & 0.7020 & 0.5635 & 0.6500 & 0.6013 & 0.5257 & 0.5485 \\
\hline$s_{1995}$ & 0.7020 & 0.5662 & 0.6041 & 0.6013 & 0.5272 & 0.5034 \\
\hline$s_{1996}$ & 0.7020 & 0.5678 & 0.5753 & 0.6013 & 0.5278 & 0.4684 \\
\hline$s_{1997}$ & 0.7020 & 0.5686 & 0.5415 & 0.6013 & 0.5281 & 0.4630 \\
\hline$s_{1998}$ & 0.7020 & 0.5691 & 0.5168 & 0.6013 & 0.5281 & 0.4355 \\
\hline$S S R$ & 0.0079 & 0.0017 & 0.0001 & 0.0031 & 0.0010 & 0.0001 \\
\hline $\mathrm{p}^{\text {-value }}{ }^{b}$ & & 0.0000 & 0.0000 & & 0.0000 & 0.0004 \\
\hline
\end{tabular}

See notes of Table 4

a Standard errors were calculated according to (20) to (22), treating each observation as a cluster

${ }^{b}$ Of an unadjusted Wald-Test of $H_{0}:(S(J-1))$ vs. $H_{1}:(S J), J=2,3$. 
Table A2. Parameter estimates, East Germany, 1990 - 98 standard errors based on independence assumption in parentheses ${ }^{a}$

\begin{tabular}{|c|c|c|c|c|c|c|}
\hline Parameter & \multicolumn{3}{|c|}{ without covariates } & \multicolumn{3}{|c|}{ with covariates } \\
\hline \multirow[b]{2}{*}{$\sigma_{\mu}^{2}$} & (S1) & (S2) & (S3) & (S1) & (S2) & (S3) \\
\hline & $\begin{array}{r}0.0740 \\
(0.0024)\end{array}$ & $\begin{array}{r}0.0296 \\
(0.0058)\end{array}$ & $\begin{array}{r}0.0239 \\
(0.0065)\end{array}$ & $\begin{array}{r}0.0298 \\
(0.0013)\end{array}$ & $\begin{array}{r}0.0122 \\
(0.0025)\end{array}$ & $\begin{array}{r}0.0239 \\
(0.0065)\end{array}$ \\
\hline$\sigma_{\nu_{1989}}^{2}$ & & $\begin{array}{r}0.0782 \\
(0.0081)\end{array}$ & $\begin{array}{r}0.1159 \\
(0.0230)\end{array}$ & & $\begin{array}{r}0.0371 \\
(0.0059)\end{array}$ & $\begin{array}{r}0.1159 \\
(0.0230)\end{array}$ \\
\hline \multirow[t]{2}{*}{$\rho$} & & 0.8518 & 0.6425 & & 0.7987 & 0.6425 \\
\hline & & $(0.0205)$ & $(0.1078)$ & & $(0.0309)$ & $(0.1078)$ \\
\hline \multirow[t]{2}{*}{$\theta$} & & -0.3922 & -0.2459 & & -0.4321 & -0.2459 \\
\hline & & $(0.0242)$ & $(0.0811)$ & & $(0.0294)$ & $(0.0811)$ \\
\hline$\alpha_{1991}$ & & & $\begin{array}{r}1.0358 \\
(0.0932)\end{array}$ & & & 1.0358 \\
\hline$\alpha_{1992}$ & & & $\begin{array}{r}1.2367 \\
(0.0902)\end{array}$ & & & $\begin{array}{r}1.2367 \\
(0.0902)\end{array}$ \\
\hline$\alpha_{1993}$ & & & $\begin{array}{r}1.5307 \\
(0.0866)\end{array}$ & & & $\begin{array}{r}1.5307 \\
(0.0866)\end{array}$ \\
\hline$\alpha_{1994}$ & & & $\begin{array}{r}1.6014 \\
(0.0993)\end{array}$ & & & $\begin{array}{r}1.6014 \\
(0.0993)\end{array}$ \\
\hline$\alpha_{1995}$ & & & $\begin{array}{r}1.8066 \\
(0.1161)\end{array}$ & & & $\begin{array}{r}1.8066 \\
(0.1161)\end{array}$ \\
\hline$\alpha_{1996}$ & & & $\begin{array}{r}1.7623 \\
(0.1632)\end{array}$ & & & $\begin{array}{r}1.7623 \\
(0.1632)\end{array}$ \\
\hline$\alpha_{1997}$ & & & $\begin{array}{r}1.9035 \\
(0.3355)\end{array}$ & & & $\begin{array}{r}1.9035 \\
(0.3355)\end{array}$ \\
\hline$\alpha_{1998}$ & & & $\begin{array}{r}1.9548 \\
(0.3781)\end{array}$ & & & $\begin{array}{r}1.9548 \\
(0.3781)\end{array}$ \\
\hline$\lambda_{1991}$ & & & $\begin{array}{r}1.0925 \\
(0.0568)\end{array}$ & & & $\begin{array}{r}1.0925 \\
(0.0568)\end{array}$ \\
\hline$\lambda_{1992}$ & & & $\begin{array}{r}1.0876 \\
(0.0492)\end{array}$ & & & $\begin{array}{r}1.0876 \\
(0.0492)\end{array}$ \\
\hline$\lambda_{1993}$ & & & $\begin{array}{r}0.9970 \\
(0.0673)\end{array}$ & & & $\begin{array}{r}0.9970 \\
(0.0673)\end{array}$ \\
\hline$\lambda_{1994}$ & & & $\begin{array}{r}0.9427 \\
(0.0535)\end{array}$ & & & $\begin{array}{r}0.9427 \\
(0.0535)\end{array}$ \\
\hline$\lambda_{1995}$ & & & $\begin{array}{r}0.8645 \\
(0.0997)\end{array}$ & & & $\begin{array}{r}0.8645 \\
(0.0997)\end{array}$ \\
\hline$\lambda_{1996}$ & & & $\begin{array}{r}0.8490 \\
(0.0589)\end{array}$ & & & $\begin{array}{r}0.8490 \\
(0.0589)\end{array}$ \\
\hline$\lambda_{1997}$ & & & $\begin{array}{r}0.7921 \\
(0.1215)\end{array}$ & & & $\begin{array}{r}0.7921 \\
(0.1215)\end{array}$ \\
\hline$\lambda_{1998}$ & & & $\begin{array}{r}0.7495 \\
(0.1026)\end{array}$ & & & $\begin{array}{r}0.7495 \\
(0.1026)\end{array}$ \\
\hline$\sigma_{\varepsilon}^{2}$ & $\begin{array}{r}0.0585 \\
(0.0019) \\
\end{array}$ & $\begin{array}{r}0.0625 \\
(0.0023) \\
\end{array}$ & $\begin{array}{r}0.0630 \\
(0.0056)\end{array}$ & $\begin{array}{r}0.0473 \\
(0.0013) \\
\end{array}$ & $\begin{array}{r}0.0520 \\
(0.0015)\end{array}$ & $\begin{array}{r}0.0630 \\
(0.0056)\end{array}$ \\
\hline$s_{1990}$ & 0.5583 & 0.2536 & 0.2017 & 0.3870 & 0.1981 & 0.2017 \\
\hline$s_{1991}$ & 0.5583 & 0.2403 & 0.2001 & 0.3870 & 0.1756 & 0.2001 \\
\hline$s_{1992}$ & 0.5583 & 0.2315 & 0.2574 & 0.3870 & 0.1637 & 0.2574 \\
\hline$s_{1993}$ & 0.5583 & 0.2255 & 0.3840 & 0.3870 & 0.1570 & 0.3840 \\
\hline$s_{1994}$ & 0.5583 & 0.2213 & 0.4511 & 0.3870 & 0.1529 & 0.4511 \\
\hline$s_{1995}$ & 0.5583 & 0.2184 & 0.5735 & 0.3870 & 0.1505 & 0.5735 \\
\hline$s_{1996}$ & 0.5583 & 0.2163 & 0.5927 & 0.3870 & 0.1489 & 0.5927 \\
\hline$s_{1997}$ & 0.5583 & 0.2148 & 0.6703 & 0.3870 & 0.1480 & 0.6703 \\
\hline$s_{1998}$ & 0.5583 & 0.2138 & 0.7162 & 0.3870 & 0.1474 & 0.7162 \\
\hline$S S R$ & 0.0101 & 0.0019 & 0.0004 & 0.0038 & 0.0008 & 0.0004 \\
\hline $\mathrm{p}^{-v^{2}} \mathrm{el}^{b}$ & & 0.0000 & 0.0000 & & 0.0000 & 0.0000 \\
\hline
\end{tabular}

See notes of Table 9

${ }^{a}$ Standard errors were calculated according to (20) to (22), treating each observation as a cluster

${ }^{b}$ Of an unadjusted Wald-Test of $H_{0}:(S(J-1))$ vs. $H_{1}:(S J), J=2,3$. 